See discussions, stats, and author profiles for this publication at: https://www.researchgate.net/publication/318277926

\title{
Strategy in manipulating transglycosylation activity of glycosyl hydrolase for oligosaccharide production
}

Article in Critical Reviews in Biotechnology · July 2017

DOI: 10.1080/07388551.2017.1339664

\section{CITATIONS}

28

3 authors, including:

4.

Hasmaliana Abdul Manas

Universiti Teknologi Malaysia

17 PUBLICATIONS 94 CITATIONS

SEE PROFILE
READS

614

Rosli Md Illias

Universiti Teknologi Malaysia

178 PUBLICATIONS 1,994 CITATIONS

SEE PROFILE

Some of the authors of this publication are also working on these related projects:

biomass extraction and enzymatic hydrolysis View project

Immobilization of Thalasosspira profundimaris for enhanced biodegradation of heterocyclic aromatic compounds View project 


\section{Strategy in manipulating transglycosylation activity of glycosyl hydrolase for oligosaccharide production}

\section{Nor Hasmaliana Abdul Manas, Rosli Md. Illias \& Nor Muhammad Mahadi}

To cite this article: Nor Hasmaliana Abdul Manas, Rosli Md. Illias \& Nor Muhammad Mahadi (2017): Strategy in manipulating transglycosylation activity of glycosyl hydrolase for oligosaccharide production, Critical Reviews in Biotechnology

To link to this article: http://dx.doi.org/10.1080/07388551.2017.1339664

曲 Published online: 06 Jul 2017.

Submit your article to this journal $\pi$

Q View related articles $๘$

View Crossmark data $\nearrow$ 


\title{
Strategy in manipulating transglycosylation activity of glycosyl hydrolase for oligosaccharide production
}

\author{
Nor Hasmaliana Abdul Manas ${ }^{\mathrm{a}, \mathrm{b}}$, Rosli Md. Illias ${ }^{\mathrm{b}, \mathrm{c}}$ and Nor Muhammad Mahadi ${ }^{\mathrm{d}}$ \\ ${ }^{a}$ Department of Chemical Engineering and Energy Sustainability, Faculty of Engineering, Universiti Malaysia Sarawak, Kota Samarahan, \\ Malaysia; ${ }^{b}$ BioMolecular and Microbial Process Research Group, Health and Wellness Research Alliance, Universiti Teknologi Malaysia, \\ Johor, Malaysia; 'Department of Bioprocess Engineering, Faculty of Chemical and Energy Engineering, Universiti Teknologi Malaysia, \\ Skudai, Malaysia; ${ }^{d}$ Comparative Genomics and Genetics Research Centre, Malaysia Genome Institute, Kajang, Malaysia
}

\begin{abstract}
Background: The increasing market demand for oligosaccharides has intensified the need for efficient biocatalysts. Glycosyl hydrolases (GHs) are still gaining popularity as biocatalyst for oligosaccharides synthesis owing to its simple reaction and high selectivity.

Purpose: Over the years, research has advanced mainly directing to one goal; to reduce hydrolysis activity of $\mathrm{GHs}$ for increased transglycosylation activity in achieving high production of oligosaccharides.

Design and methods: This review concisely presents the strategies to increase transglycosylation activity of GHs for oligosaccharides synthesis, focusing on controlling the reaction equilibrium, and protein engineering. Various modifications of the subsites of GHs have been demonstrated to significantly modulate the hydrolysis and transglycosylation activity of the enzymes. The clear insight of the roles of each amino acid in these sites provides a platform for designing an enzyme that could synthesize a specific oligosaccharide product.

Conclusions: The key strategies presented here are important for future improvement of GHs as a biocatalyst for oligosaccharide synthesis.
\end{abstract}

\section{ARTICLE HISTORY}

Received 20 December 2016 Revised 21 March 2017

Accepted 6 May 2017

\section{KEYWORDS}

Oligosaccharide; glycosyl

hydrolase; reaction equilibrium; protein engineering; oligosaccharide synthesis; hydrolysis; transglycosylation

\section{Introduction}

Demand for so-called "functional foods" is impressively growing due to the increasing health awareness amongst consumers. Oligosaccharides have attracted a lot of attention as it has the potential to be used as dietary carbohydrates and food additives to improve the nutritional value of the food. Oligosaccharides have been used as prebiotics for stimulating the growth and activity of beneficial intestinal microflora $[1,2]$ that will assist in digestion, nutrient absorption, produce vitamins, enhance the immune system of the host, and suppress the growth of putrefactive pathogenic bacteria [3].

Oligosaccharides can be extracted from nature, but in vitro synthesis is preferred because it provides a high yield to fulfill the great market demand. The considerable development in oligosaccharides synthesis can be observed in recent years especially aiming at acquiring high yield, low cost, together with a robust and simple process. The shift from chemical synthesis to enzymatic synthesis for oligosaccharides production has been observed as the enzymatic method is more promising.
The development in enzyme technology leads to innovation of improved enzymes to be used as biocatalysts for oligosaccharides synthesis. A major breakthrough in the protein engineering of glycosyl hydrolases (GHs) for oligosaccharides synthesis was the invention of glycosynthase, a mutant GH that catalyzes the synthesis of glycosidic linkages without hydrolyzing the newly formed glycosidic linkages. This has been extensively reviewed [4,5]. This review focuses on strategies to improve transglycosylation activity of $\mathrm{GH}$ for higher oligosaccharides synthesis using a reaction equilibrium control strategy and together with protein engineering.

\section{Production of oligosaccharides}

The world has witnessed a fast growth of the functional food market driven by an overwhelming consumer consciousness for healthier foods. According to the report by the Leatherhead Food Research, the global functional food market was predicted to increase $25 \%$ by 2017 compared to 2013, reaching USD 54 billion in value [6]. The United States, Europe, and Japan are

CONTACT Nor Hasmaliana Abdul Manas anhasmaliana@unimas.my Department of Chemical Engineering and Energy Sustainability, Faculty of Engineering, Universiti Malaysia Sarawak, 94300 Kota Samarahan, Sarawak, Malaysia

(C) 2017 Informa UK Limited, trading as Taylor \& Francis Group 
among the largest markets for these functional foods as supplements. Meanwhile, China, India and Latin America are emerging markets. Ever since, oligosaccharides were introduced as "foods for specified health use" (FOSHU) in 1991 by Japan, the increasing interest for functional oligosaccharides was comparable to the market demand for functional foods [7].

The increasing market demand has urged an effort for researching a reliable technique for large-scale production of oligosaccharides. Conventionally, oligosaccharides are extracted from natural sources. For large-scale application, chemical or enzymatic synthesis is used. Chemical synthesis is not preferred in industry because it is expensive, laborious and results in low yields. The process requires continuous monitoring and is not environmentally friendly as it often requires the use of pure and hazardous chemicals [3]. Moreover, the process involves tedious protection, deprotection and activation strategies to control the regioselectivity and stereochemistry of the resulting oligosaccharide [8], which are not desirable and nonrealistic for large-scale production. Currently, oligosaccharides are produced by enzymatic glycosylation. The main advantage of using enzymes as biocatalysts is that it eliminates protection and deprotection steps because it can control both regioselectivity and stereoselectivity of glycosylation [9].

Enzymatic synthesis does not require protection and deprotection of the substrate hydroxyl groups and has complete control of the anomeric center configuration [10]. Glycosyl transferases (GTs) and GHs are enzymes that have been used during oligosaccharides production. GTs are good biocatalysts for oligosaccharides synthesis, provided that the enzymes have great specificity to allow the formation of precisely constructed oligosaccharides [9]. Synthesis of oligosaccharides using GTs have been comprehensively reviewed [4,11-14] and it has been widely used even during a large-scale production. However, their application is somehow limited by the poor availability of the enzymes and the use of complex and expensive activated substrates [8]. The enzymes are unstable in a solution, which make them unrealistic for industrial applications [3]. These limitations lead to the use of GHs, enzymes that could catalyze both the hydrolysis and transglycosylation for synthesizing oligosaccharides. GHs are preferred over GTs because these enzymes are easily procured and they act on a simple and cheap donor, such as monosaccharides and disaccharides. These enzymes are stable, easy to handle and functional without the need for cofactors [15]. As summarized in Table 1, GHs have been widely employed for the production of various oligosaccharides.

\section{Structure, function, and mechanism of GH for oligosaccharides synthesis}

GHs are a group of enzymes that catalyze the hydrolysis of the glycosidic bond. There are some GHs that are capable to catalyze the formation of glycosidic bond, which have been exploited in the production of oligosaccharides. The availability of crystal structure data of various GHs aided researchers to understand the active site architecture and to reveal the mechanism of action that cause these enzymes to "moonlight". It has been described by Davies and Henrissat [32] that the active site topologies of $\mathrm{GHs}$ generally fall into the pocket type, the cleft type and the tunnel type. Despite different topologies, these active sites are commonly comprised of several subsites numbered as negative $(-n)$ subsites and as positive $(+n)$ subsites [33], as illustrated in Figure 1.

"Docking" of a carbohydrate molecule (substrate) into the enzyme active site involves the interaction of each monosaccharide unit with specific amino acids located in each subsite. Following substrate docking, the glycosidic bond hydrolysis takes place via general acid catalysis that involves two key residues, which are a proton donor (acid catalyst) and a nucleophile/ base [34], as shown in Figure 2. The hydrolysis can occur via either two major mechanisms, which is a retaining or inverting mechanism, each produces hydrolysis products of different anomeric configuration. For a retaining mechanism (Figure 2(a)), acid catalyst (A) donates a proton to the glycosidic bond oxygen, which is the oxygen between two glucose molecules at the subsites -1 and +1 . Consequently, the $\mathrm{C} 1$ of glucose at subsite -1 is attacked by the nucleophile (B) forming an oxocarbonium ion-like transition state, followed by the formation of a covalent intermediate between the glucose molecule and the nucleophile residue. Next, the protonated molecule ( $\mathrm{ROH})$ at subsite +1 leaves the active site. This is the glycosylation step. The covalent bond is subsequently attacked by a water molecule and an oxocarbonium ion-like transition state is formed again. Meanwhile, the acid catalyst (A) residue in the form of a base accepts the hydrogen from incoming water and performs a nucleophilic attack on the $\mathrm{C} 1$ of the glucose at subsite-1. The oxocarbonium bond between the glucose molecule at subsite -1 and the acid catalyst residue is replaced by the oxygen of the incoming water molecule at subsite +1 , forming a new hydroxyl group at the C1 position of the glucose at subsite -1 with the same stereochemistry of the substrate. This step is known as deglycosylation. In the presence of a nucleophile other than water 
CRITICAL REVIEWS IN BIOTECHNOLOGY -3

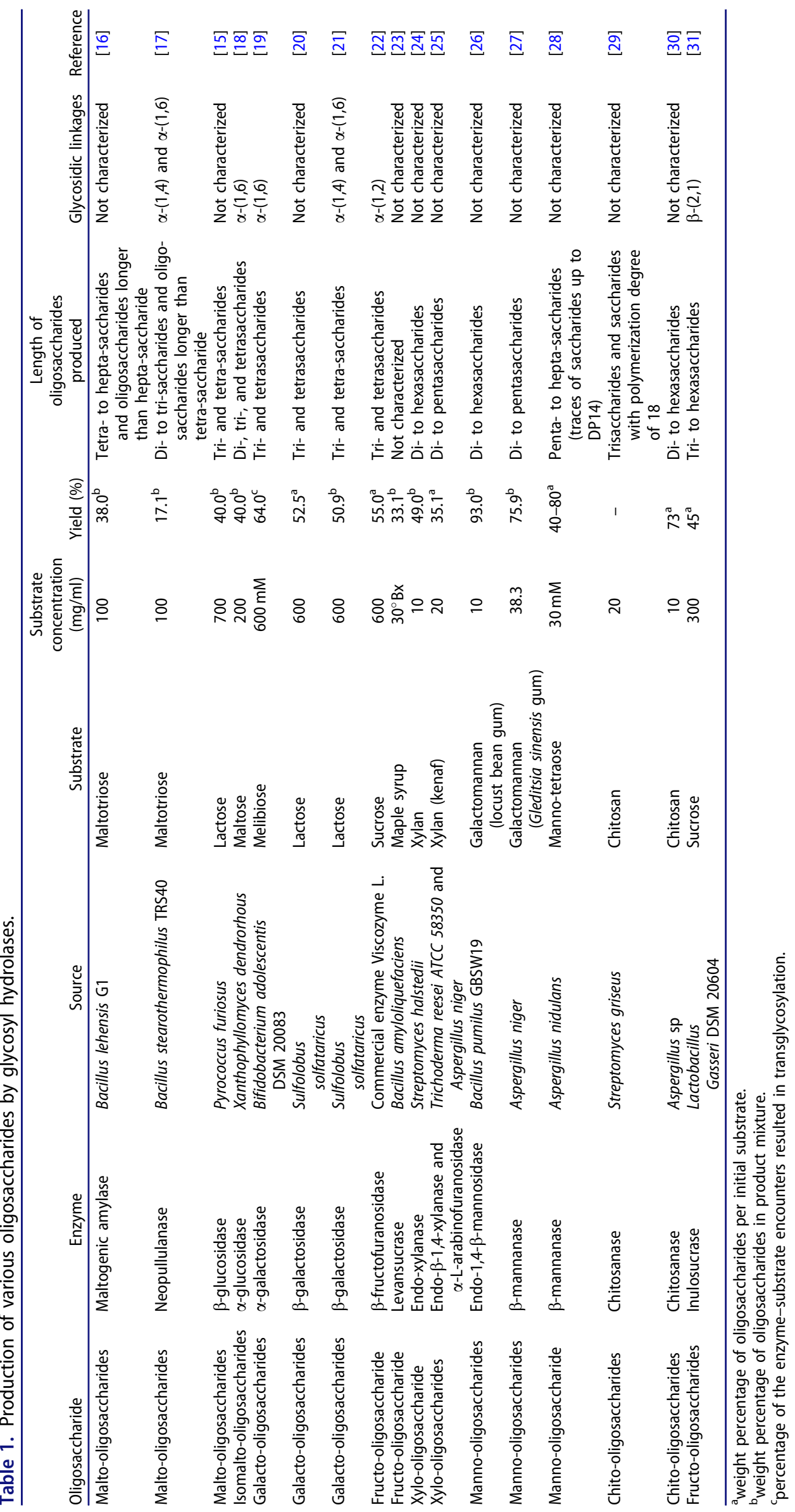


(a)

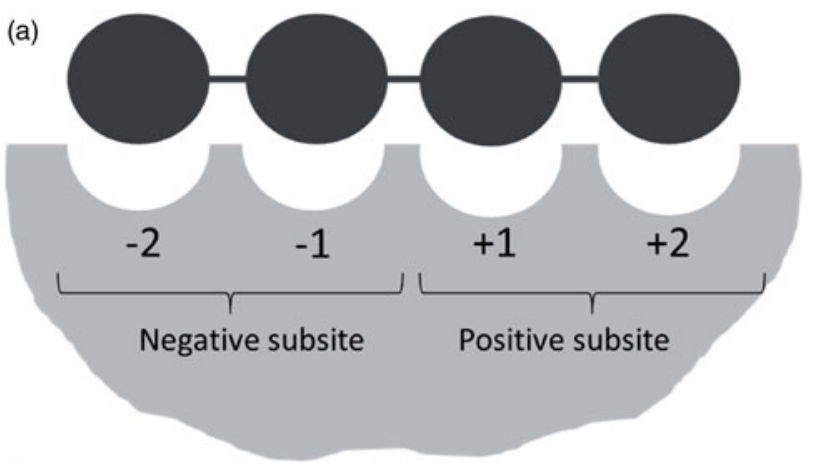

(b)

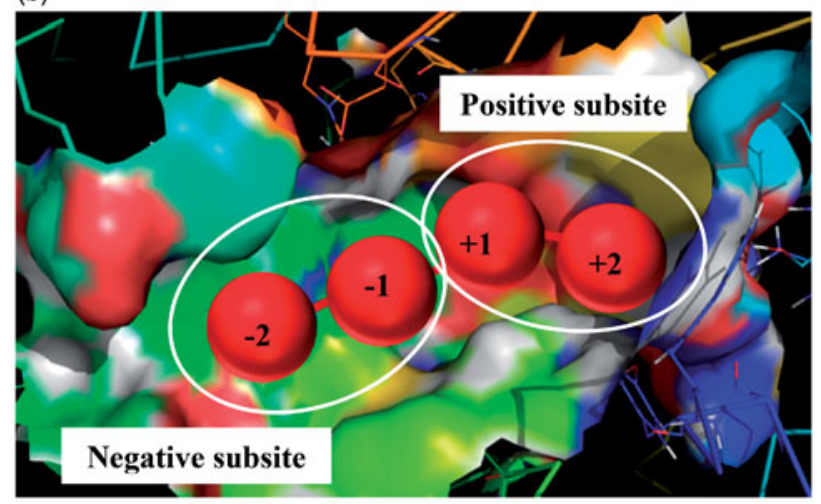

Figure 1. Common structure of GHs active site. (a) Schematic diagram of the negative and positive subsites. (b) Example of active site structure showing negative and positive subsites. Circles and spheres represent sugar units joined by glycosidic linkages.
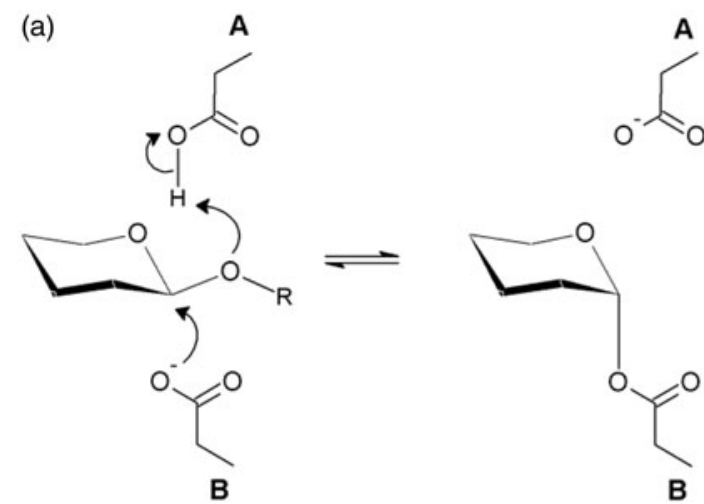

A
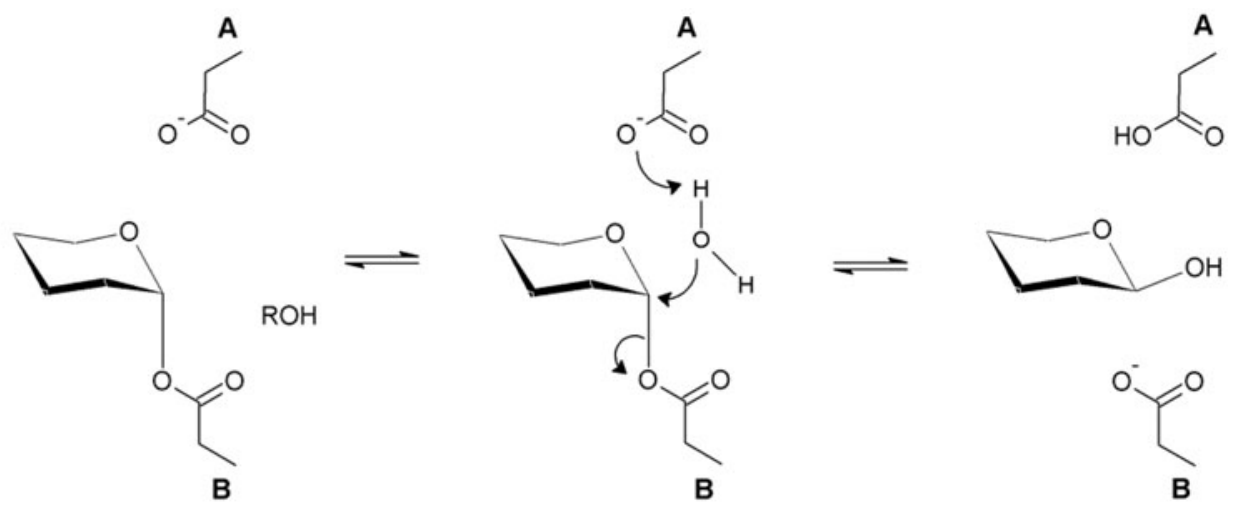

(b)
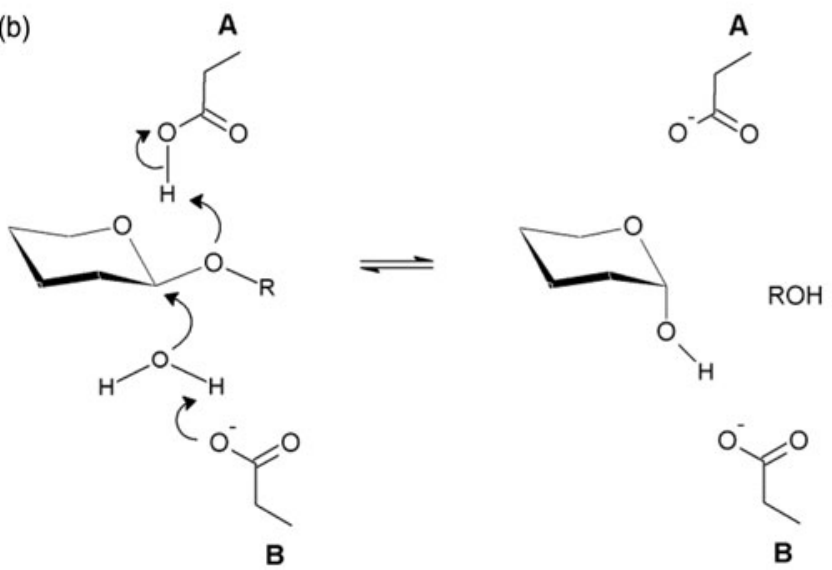

Figure 2. Glycosidic bond hydrolysis by GH via (a) retaining and (b) inverting mechanism. A is an acid catalyst (proton donor) residue, $B$ is a nucleophile/base residue and $\mathrm{R}$ is the leaving group. For transglycosylation, the attacking water molecule is replaced by a sugar acceptor molecule. 
(e.g. a sugar acceptor), transglycosylation takes place whereby a new glycosidic linkage between the sugar unit of the donor molecule at subsite -1 and the sugar unit of the incoming acceptor molecule at subsite +1 is formed. In retaining GHs, interactions between glycosyl at subsite -1 and nucleophile residue plays major role in catalysis, either hydrolysis or transglycosylation in such a way it stabilizes the reaction, lowering the free energy barrier, and keeps the substrate in a conformation that is preactivated for catalysis [35]. For inverting mechanisms (Figure 2(b)), the protonation of the glycosidic oxygen and the attack of the water molecule is activated by the base residue, which occurs concurrently. This mechanism produces a product with an opposite stereochemistry to the substrate $[34,36]$.

The two catalytic residues of $\mathrm{GHs}$ divide the active site cleft into negative and positive subsites [37]. The negative subsite is a region for a substrate or donor to bind to the active site of an enzyme. On the other hand, the positive subsite is a region for product release or for acceptor binding. For an efficient hydrolysis reaction, strong and specific substrate binding is required at the negative subsite whereas a weaker and less specific binding is required at the positive subsite to ease product release. In contrast, for an efficient transglycosylation to occur, stronger binding is required at the positive subsite for the accommodation of an acceptor molecule.

Strong binding affinity is contributed by the characteristics of the binding cleft, such as the number of subsites with negative free energies and the type of amino acids present in the subsite. Detachment of the cleaved substrate is easier from a shorter positive subsite. It has been demonstrated that the release of the hydrolyzed substrate became rate-limiting in an enzyme with a longer positive subsite [38]. Compared to the enzyme with a shorter positive subsite, sugars are weakly bound and easily released [37]. Furthermore, enzymes containing amino acids that strongly bind an acceptor molecule in the positive subsite showed higher transglycosylation activities [38-44]. Amino acids, such as Trp, Tyr, Phe, Arg, and Asn contribute to the high affinity of acceptor binding in the positive subsite as these residues form various interactions with the bound sugar molecule. The substitution of these amino acids in the positive subsite resulted in diminished acceptor binding and subsequently, caused a substantial reduction of transglycosylation rate. Weak binding of sugars at the positive subsite increases the rate of the leaving molecule after hydrolysis and increases the rate of water diffusion into the subsite +1 to complete the hydrolysis reaction [38].

\section{Strategies to improve transglycosylation of GHs}

Hydrolysis and transglycosylation occurs simultaneously at the same active site of a $\mathrm{GH}$. Therefore, a high yield production of oligosaccharides is quite challenging. Although $\mathrm{GHs}$ have been effectively used to produce oligosaccharides, the hydrolysis activity is a major bottleneck in the process because hydrolysis is a thermodynamically more favorable reaction. Even if the transglycosylation reaction occurs, produced oligosaccharides are usually susceptible to re-hydrolysis by the enzyme, resulting in a poor yield [9]. Transglycosylation is a kinetically controlled reaction, thus, maximum yield can be achieved by careful monitoring of it [45]. The transglycosylation efficiency of $\mathrm{GH}$ greatly depends on competition between the sugar acceptor and the water molecule in the active site [9]. Appropriate strategies are presented here for a high yield production of oligosaccharides using GHs. Screening and characterization of the enzyme from various sources have been progressively carried out. Choosing the proper enzyme is one of the strategies to obtain the desired product specificity as different enzymes give different yields, different type of linkages formed, and different product inhibition. Moreover, different sources of the enzyme may produce a product of different stereoselectivity and regioselectivity [46]. On another note, to make the enzyme favorably accommodate a sugar acceptor rather than a water molecule, the reaction equilibrium can be controlled by reversing the hydrolysis reaction through optimization of transglycosylation conditions. Reconstruction of the enzymes' active site by rational design and protein engineering is also one of the effective strategies for enhancing transglycosylation activity of the enzyme.

\section{Source of enzyme}

The efficiency of transglycosylation, the yield of oligosaccharides, the saccharide composition, the degree of polymerization of oligosaccharides, and the regiochemistry of the glycosidic linkages of oligosaccharides depends on the enzyme source. A wide spectrum of galacto-oligosaccharides produced during lactose conversion by various $\mathrm{GHs}$ has been comprehensively reviewed by Torres et al. [47]. Similarly, a similar situation applies to other oligosaccharides. Different sources of enzymes use various types of substrate, a spectrum of initial substrate concentrations and 
Table 2. Optimum temperatures and $\mathrm{pHs}$ for hydrolysis and transglycosylation for different glycosyl hydrolases from various sources.

\begin{tabular}{|c|c|c|c|c|}
\hline Enzyme & Source & Hydrolysis $\left({ }^{\circ} \mathrm{C}\right)$ & Transglycosylation $\left({ }^{\circ} \mathrm{C}\right)$ & Reference \\
\hline \multicolumn{5}{|l|}{ Temperature } \\
\hline Amylosucrase & Deinococcus geothermalis & $45^{\circ} \mathrm{C}$ & $25^{\circ} \mathrm{C}$ & [48] \\
\hline Endo- $\beta$-galactosidase & Escherichia freundii & $37^{\circ} \mathrm{C}$ & $1^{\circ} \mathrm{C}$ & [49] \\
\hline Maltogenic amylase & Bacillus lehensis G1 & $40^{\circ} \mathrm{C}$ & $30^{\circ} \mathrm{C}$ & [16] \\
\hline$\beta$-galactosidase & Bacillus circulans & $30^{\circ} \mathrm{C}$ & $-5^{\circ} \mathrm{C}$ & [50] \\
\hline Levansucrase & Bacillus amyloliquefaciens & $30^{\circ} \mathrm{C}$ & $\begin{array}{c}30^{\circ} \mathrm{C}\left(66^{\circ} \mathrm{Bx}\right) \\
8{ }^{\circ} \mathrm{C}\left(15 \text { and } 30^{\circ} \mathrm{Bx}\right)\end{array}$ & [23] \\
\hline Dextransucrase & Leuconostoc mesenteroides B-512FMC & $20^{\circ} \mathrm{C}$ & $30^{\circ} \mathrm{C}$ & [51] \\
\hline Levansucrase & Lactobacillus sanfranciscensis TMW & $50^{\circ} \mathrm{C}$ & $20^{\circ} \mathrm{C}$ & [52] \\
\hline Inulosucrase & $\begin{array}{l}\text { Lactobacillus } \\
\quad \text { Gasseri DSM } 20604\end{array}$ & $45^{\circ} \mathrm{C}$ & $55^{\circ} \mathrm{C}$ & [31] \\
\hline \multicolumn{5}{|c|}{ - } \\
\hline Exo- $\beta$-(1,4)-galactanase & Aspergillus niger & 3.5 & 7.0 & [53] \\
\hline Hyaluronidase & Bovine testicular & 5.0 & 7.0 & [54] \\
\hline Endo- $\beta$-glucanase & Rhodotorula glutinis & 4.5 & 2.0 & [55] \\
\hline$\beta$-glucosidase & Aspergillus niger & 4.5 & $3.0-7.0$ & [56] \\
\hline$\beta$-glucosidase (N220Y variant) & Thermotoga neapolitana & 5.5 & $5.0-11.0$ & [57] \\
\hline
\end{tabular}

produce different yields of oligosaccharides, degrees of polymerization, and types of glycosidic linkages formed (Table 1). The unique active site structure between different sources of enzyme provides a distinct spatial orientation for accommodation of the sugar acceptor in the active site, thus generating variations in the stereochemistry of the newly synthesized glycosidic linkages $[47,58]$. Some GHs also exhibited wide acceptor specificity [19,59-63]. These properties have the potential to be exploited in the production of saccharides with the desired composition. The variation in the number of positive subsites between enzymes is another probable factor that contributes to the various degrees of polymerization of oligosaccharides produced.

Elucidation of the mode of action and kinetics of $\mathrm{GHs}$ from various sources is important because the knowledge could be used as a basis for designing a precise reaction composition for specific oligosaccharide synthesis. For example, the mechanism of cyclodextrin ring-opening was exhibited by cyclodextrin-degrading enzymes and it has been successfully exploited to produce malto-oligosaccharides of particular lengths [16,64,65]. As reported by Yang et al. [64], Pyrococcus furiosus amylase exhibited higher affinity toward $\alpha-C D, \beta-C D$, and $\gamma-C D$, compared to their linear malto-oligosaccharide counterparts which are maltohexaose, maltoheptaose, and maltooctaose, respectively. Cyclodextrin would firstly be hydrolyzed via the enzyme ring-opening catalytic mechanism before the linearized malto-oligosaccharide was further hydrolyzed to smaller malto-oligosaccharides. Maltogenic amylase from Bacillus lehensis G1 and Thermofilum pendens demonstrated similar reaction modes, whereby the hydrolysis of cyclodextrin consisted of linearization steps which involved the cleavage of one $\alpha-1,4-g$ lycosidic linkage of every cyclodextrin molecule followed by hydrolysis of the linearized product $[16,65]$. Based on these understandings, designing a reaction with specific components to produce the desired length of oligosaccharides is possible.

\section{Reaction equilibrium control: mechanism of activity switching}

Identifying ideal conditions are crucial in carbohydrate synthesis using $\mathrm{GHs}$ in order to direct the reaction toward transglycosylation without allowing significant enzymatic degradation of the synthesized product. Reactions catalyzed by most GHs are kinetically controlled, whereby the reaction equilibrium can be shifted to favor hydrolysis or transglycosylation by manipulating the conditions. The hydrolysis and transglycosylation circumstances catalyzed by $\mathrm{GH}$ s are highly influenced by water activity (refer to Figure $3(a, b)$ for illustrations). In the presence of a suitable nucleophile, other than water, the enzyme can transfer the glycosyl residues to form a glycosidic linkage [15]. The equilibrium control approach is carried out since the hydrolysis activity is a reversible reaction. Reversed hydrolysis could be achieved by suppressing water activity in the reaction mixture by two methods. The first method is increasing the concentration of the acceptor molecule by incubating the enzyme with highly concentrated acceptor solution [3]. The second method is incorporating organic solvents into the reaction to reduce the water activity [9].

The improved productions of oligosaccharides (particularly longer oligosaccharides) have been demonstrated by various studies when the substrate concentration was increased. High substrate 
(a)

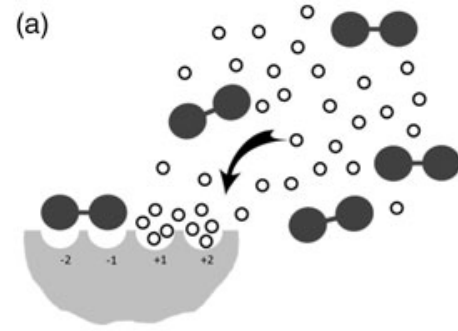

High water activity (b)

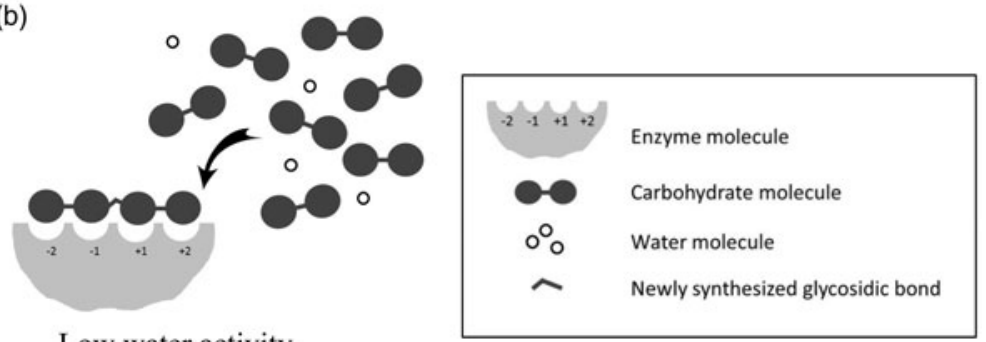

Low water activity

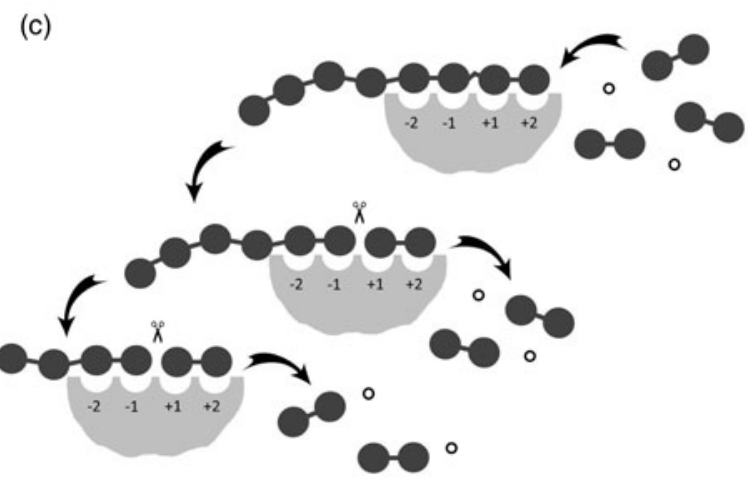

High enzyme concentration

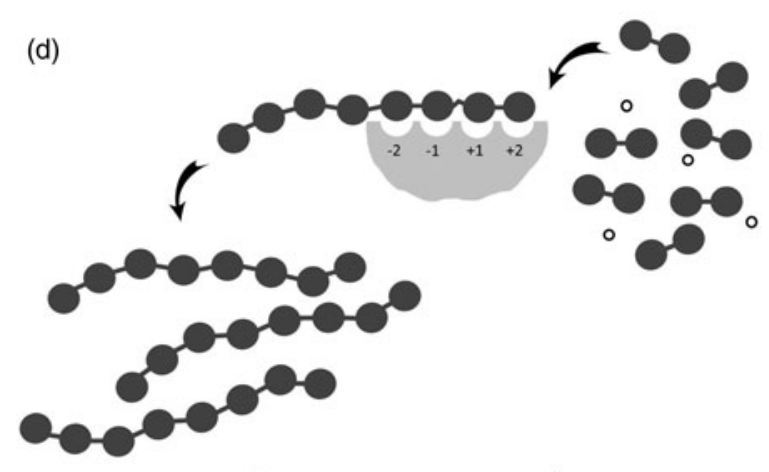

Low enzyme concentration

Figure 3. Transglycosylation activity of enzyme at different condition. (a) At high water activity, water molecules accommodate the active site and hydrolysis is preferred than transglycosylation. (b) At low water activity, carbohydrate acceptor molecules accommodate the active site and transglycosylation is favored. (c) At high enzyme concentration, more active sites are available for re-hydrolysis of the transglycosylation products, thus reducing transglycosylation yield. (d) At low enzyme concentration, production of longer products and the transglycosylation yield increases.

concentration suppressed the hydrolysis activity of the enzyme by limiting water availability (Figure $3(b)$ ). Therefore, longer oligosaccharides accumulated as the final products without being re-hydrolyzed. In addition, it provided the reaction with more acceptor molecules for an increased synthesis rate [66]. With an increased concentration, the amount of hydroxyl groups of carbohydrates is higher compared to those of water, which act as acceptors for transglycosylation. It has been shown that the transglycosylation yield of $\alpha$-glucosidase from Xanthophyllomyces dendrorhous, which consisted of trisaccharides and tetrasaccharides, was improved to $167.1 \mathrm{~g} / \mathrm{l}$ when the maltose concentration was increased to $525 \mathrm{~g} / \mathrm{l}$ compared to the yield of $47.1 \mathrm{~g} / \mathrm{l}$ when $200 \mathrm{~g} / \mathrm{l}$ maltose was used [18]. The yield of branched tetraose and pentose in the branched oligosaccharides production using maltogenic amylase from Bacillus stearothermophilus was also increased when the higher substrate concentration was used [67]. In other studies, transglycosylation activity of maltogenic amylase from $B$. lehensis G1 was demonstrated to be dominant at higher maltotriose concentration [16]. Transfructosylation products of levansucrase activity was also reported to be higher when using a high viscosity maple syrup compared to lower viscosity maple syrup $[23,52,68]$. The transglycosylation-to-hydrolysis ratio of glucosidases continued to increase as the substrate concentration increased [69]. The galacto-oligosaccharide synthesis during lactose hydrolysis by $\beta$-galactosidase further demonstrated a significant increase with enhanced lactose concentrations [70]. Oligosaccharides production by donor-acceptor condensation reaction of a glycosynthase, an engineered 1,3-1,4- $\beta$-glucanase of Bacillus licheniformis, was also directly proportional to the acceptor concentration [71].

Incorporation of organic solvents into the reaction mixture could lower the water activity, therefore, increasing the production of oligosaccharides. In the production of malto-oligosaccharides using maltogenic amylase from Brachybacterium sp. strain LB25, the addition of dimethyl sulfoxide (DMSO) increased the production of maltotetraose and improved the product ratio of maltotriose hydrolysis to glucose and maltose. The addition of ethanol, 2-propanol or DMSO also increased the transglycosylation-to-hydrolysis ratio of $B$. lehensis G1 maltogenic amylase. Furthermore, the product selectivity for maltopentaose was improved [16]. A similar finding was also reported by Kumar and Khare 
[72], in which the presence of solvent favors maltotetraose yield by a maltooligosaccharide-forming $\alpha$-amylase from Marinobacter sp. EMB8 and enhanced the transglycosylation activity of endo- $\beta$ - $\mathrm{N}$-acetylglucosaminidase from Arthrobacter protophormiae [73].

The addition of solvents at low concentration inhibited the hydrolysis of longer oligosaccharides by changing the enzyme conformation and displacing the hydration layer in the catalytic site of the enzyme [74]. The displacement of the water molecule in the enzyme active site causes the reduction in hydrolysis activity as fewer water molecules are available to act as an acceptor for hydrolysis. Retardation of water activity also promotes a high reaction rate of the hydrophobic compound. However, the addition of the solvent would possibly lead to dehydration and loss of activity because of the structural changes that could cause enzyme denaturation [75]. Therefore, enzymes under co-solvent conditions often suffer low activity. In order to overcome this problem, co-lyophilization of enzymes with cyclodextrin provides a solution. Cyclodextrins are cyclic oligosaccharides of anhydroglucose units linked by $\alpha-1,4$ glycosidic bonds. It has been demonstrated that co-lyophilization of $\beta$-galactosidase of Aspergillus oryzae with $\beta$-cyclodextrin significantly improved its synthetic activity in the presence of the triethyl phosphate solvent [76]. As a result of the co-lyophilization, the enzyme and cyclodextrin form hydrophilic interactions or hydrogen bond to produce a complex that is thermodynamically stable in organic solvents $[77,78]$. Enzyme stabilization by cyclodextrins has been reported in several studies and it also provides more active enzyme conformation [77-80]. Addition of salt can also reduce water activity to promote high transglycosylation activity. A study reported that production of hexa$\mathrm{N}$-acetyl-chitohexaose and hepta-N-acetylchitoheptaose by transglycosylation activity of a chitinase increased with the addition of ammonium sulfate into the reaction buffer [81].

Although transglycosylation was usually favored over hydrolysis at low water activity, however, a study by Cruz-Guerrero et al. [82] reported the opposite effect. Longer galacto-oligosaccharides were produced at higher concentrations when water activity was increased. Hansson and Adlercreutz [83] also reported that the glycosyl-enzyme $\beta$-glucosidase CelB could accept a large nucleophile for its transglycosylation reaction when there was an increase in internal flexibility mediated by increasing water activity. It is known that the enzyme conformation changes according to the water activity. At higher water activity, the enzyme becomes more flexible. On the other hand, the enzyme becomes more rigid at lower water activity. Higher enzyme flexibility allows the accommodation of larger molecules (i.e. carbohydrates) for glycosidic transfer. In contrast, smaller molecules (i.e. water) are favored by the rigid enzyme [82]. Although water molecules are the competing nucleophilic for transglycosylation, their activity could also impose various effects toward the selectivity of the enzyme for the acceptor molecules.

The concentration of the enzyme in a reaction mixture correspondingly contributes to the yield of transglycosylation reaction (Figure 3(c,d)). An enzyme with a processive nature of transglycosylation activity produces high amounts of high molecular weights transglycosylation products at low enzyme concentrations, as shown in Figure 3(d). Processivity occurs when the acceptor molecule in the reaction is continuously added to the donor molecules that are covalently attached to the enzyme active site. Therefore, the lower the amount of the enzyme active site that is available for synthesis, the longer will be the synthesis products formed. It has been demonstrated that the molecular weight of synthesized dextrans were inversely proportional to the dextransucrase concentration [51]. Transglycosylation activity of $B$. lehensis $\mathrm{G} 1$ was also dominant at lower enzyme concentrations. Addition of more enzymes would only shift the reaction equilibrium toward hydrolysis because more active sites would be available to accommodate the elongated transglycosylation products for hydrolysis [16]. However, in other example, the yield of the transglycosylation product of amylosucrase activity is higher when more enzymes are added to the reaction mixture [48]. Therefore, various enzymes might exhibit a different transglycosylation activity effect toward the enzyme concentration.

The effects of temperature on transglycosylation activity of GHs may vary. Transglycosylation activities of several GHs are reported to be dominant over hydrolysis activity at a lower temperature $[16,48,49]$. The optimum temperatures for hydrolysis and transglycosylation activity of different GHs are summarized in Table 2. A lower temperature suppresses hydrolysis of a transglycosylation product upon formation $[16,49]$. A study revealed that the synthesis of oligosaccharides in a frozen state produced a higher yield due to reduced water concentrations and high solute concentration in the frozen state. Furthermore, products are relatively more stable at a lower temperature [50]. These factors contribute to greater transglycosylation yield. In some cases, the rate of synthesis is higher at a higher temperature compared to a lower temperature. For example, polymerization of dextran by a dextransucrase takes place at the higher rate as the temperature increased, due to the increased rate of transglycosylation at higher temperatures $[51,84]$. High diffusion of 
the dextran at high temperature is crucial in order to bind to the acceptor-site [84]. Production of galacto-oligosaccharides using $\beta$-galactosidase is also favored at a higher temperature because temperature can increase the solubility of lactose, which is the substrate for the transglycosylation reaction [85]. In addition, the production of fructo-oligosaccharides from highly viscous maple syrup using levansucrase prefers a high temperature environment due to increased diffusional mass transfer of acceptor molecules [23].

Hydrolysis and transglycosylation reactions take place in distinct $\mathrm{pH}$ values as depicted in Table 2 . This suggested that the ionization states of certain residues in the active site determine the favored interactions, either with water or a sugar acceptor. Seidle and Huber [56] and Lundemo et al. [57] reported that hydrolysis of $\beta$-glucosidase and variants, respectively, was $\mathrm{pH}$-dependent, while transglycosylation was not. Hydrolysis reactions commonly depend on $\mathrm{pH}$ because variation of $\mathrm{pH}$ causes enzyme conformational changes. However, during the transglycosylation reaction, the binding of the sugar acceptor could prevent such conformational changes. Therefore, transglycosylation activity is shown not to be affected by $\mathrm{pH}$ changes. It was also speculated that high $\mathrm{pH}$ caused deprotonation of Tyr, an important residue that is often found with a hydrogen bond to the catalytic nucleophile [86]. Protonation of this residue is needed to form a hydrogen bond with nucleophile for stabilization during the transition state in the deglycosylation step for assisting covalent bond cleavage. This stabilization, however, is not required for transglycosylation. This difference can be utilized to improve the yield of the transglycosylation reaction.

The reaction equilibrium control approach is effective to improve the transglycosylation activity of $\mathrm{GHs}$. However, this approach is subject to some limiting factors. Close monitoring is necessary to ensure that the reaction was stopped at the point of maximum transglycosylation products [18]. It also struggles with an unfavorable thermodynamic balance. The use of high substrate concentrations and the addition of an organic solvent only improve not more than $15 \%$ of the transglycosylation products [87]. Furthermore, in order to reduce water activity for transglycosylation to become dominant, the sugar concentration must be between 70 and $80 \%$. The reaction rates are generally very slow at these concentrations, although the enzyme is stabilized by the high sugar concentration [88]. Hence, a more promising method has evolved, which is by optimizing the enzyme structure, owing to the advances in the protein structure-function studies.

\section{Protein engineering: toward tailored oligosaccharides synthesis}

The availability of crystal structure data of GHs leads to a greater understanding of the enzyme catalytic machinery that is capable of catalyzing both hydrolysis and transglycosylation activities. Many studies have attempted to manipulate or reconstruct the enzyme active site structure in order to diminish the hydrolysis activity for increased transglycosylation activity. Glycosynthase, a specifically mutated glycosidase, has been invented in which an essential nucleophile was mutated to yield an enzyme with no hydrolysis activity. This enzyme catalyzes the formation of a glycosidic bond when a suitable activated glycosyl donor is provided. Interestingly, the newly synthesized glycosidic linkage will not be hydrolyzed by the enzyme [9]. Although glycosynthase was successfully used to produce a high yield of transglycosylation product, high enzyme concentrations, and longer reaction times are required [87]. Moreover, they cannot act on simple and natural substrates because activated glycosyl donors are needed for glycosylation to take place.

The key to a successful strategy relies upon an understanding of deglycosylation transition state properties that determine the hydrolysis and transglycosylation partition. Two transition states (TS) are formed by retaining GHs: TS1 preceding the formation of the glycosyl-enzyme intermediate and TS2 characterizing disruption of the covalent intermediate and preceding formation of the reaction products. The TS is mainly stabilized to different extents by non-catalytic active site residues, which are hydrogen-bonded to the sugar moiety [89]. Increasing the energy barrier of the TS could render acceptor-mediated deglycosylation favorable than water-mediated deglycosylation, as the sugar acceptor provides greater interaction to overcome the energy barrier. As concluded by Bissaro et al. [90], these can be achieved by altering interactions in the negative subsite to destabilize TS2 for water-mediated deglycosylation or promoting interactions in the positive subsites so that TS2 energy for the acceptor is lower than TS2 for water. Four main strategies are presented here in the protein engineering of $\mathrm{GHs}$ for enhanced transglycosylation activity, including altering interactions in both subsites. Because hydrolysis activity is the major bottleneck for oligosaccharide synthesis using GHs, the strategies were also aimed to reduce hydrolysis activity by increasing the acceptor affinity at the positive subsite and to reduce diffusion of the water molecule to the active site. This has been achieved by the introduction of aromatic and hydrophobic amino acids in the positive subsites and the reduction of steric interference 
in the positive subsite to increase the number of subsite that could accommodate a longer sugar acceptor molecule.

\section{Controlling water accessibility}

Water is known as the competing nucleophile for transglycosylation activity. By using site-directed mutagenesis, the active site could be manipulated in a way that water molecules are mediated away or excluded from entering it. One of the important factors that can influence the accommodation of water in the active site is the hydrophilicity or hydrophobicity level. A hydrophilic active site favors the accommodation of water, thus catalyzing more effective hydrolysis activity than transglycosylation. It has been reported that mutation of hydrophobic amino acids to hydrophilic amino acids in the $B$. stearothermophilus maltogenic amylase active site improves its hydrolysis and decreased its transglycosylation activity to produce more maltose [91].

As shown in Figure 4, the introduction of hydrophobic amino acids in the positive subsite can reduce diffusion of water into the active site and increase the binding affinity of the acceptor molecule for transglycosylation. Many glycosyltransferases have hydrophobic residues at subsite $+1 \quad[17,92-96]$ and increasing

(a)

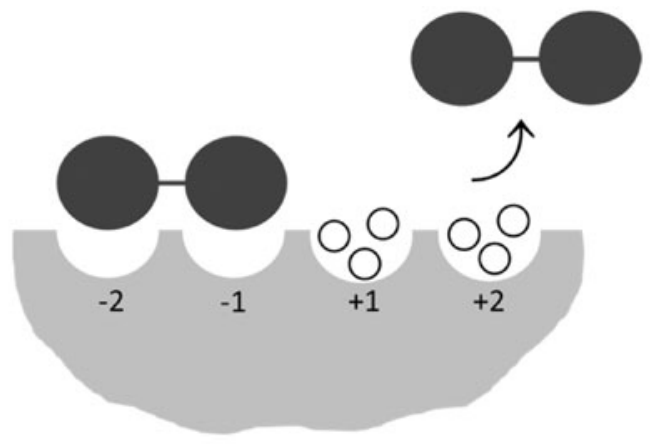

Without aromatic amino acids or hydrophobic amino acids, water is favored

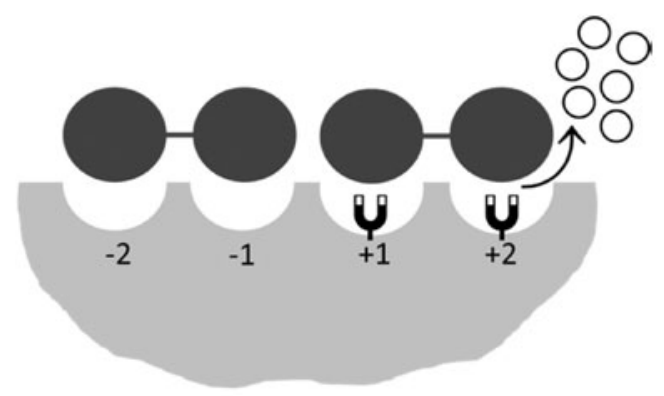

With aromatic amino acids or hydrophobic amino acids, sugar acceptor is favored and water is repelled hydrophobicity at subsite +1 of $\mathrm{GH}$ improved its transglycosylation activity [97]. The importance of a hydrophobic tryptophan residue at positive subsite 4- $\alpha$-glucanotransferase from $P$. furiosus for transglycosylation has been proved when a mutation to the hydrophilic histidine amino acid residue resulted in a substantial decrease in transglycosylation activity with little effect on its hydrolysis activity. This residue provides additional hydrophobic interactions with an acceptor molecule at subsites $+1,+2$, and +3 . The substitution reduced the hydrophobicity of the active site environment; and thus, resulted in weaker binding of acceptor molecules [98]. On the other hand, it was reported that Tyr, Trp, and His residues formed strong hydrogen bonds with water molecules in the active site of $\alpha$-amylase, an enzyme with no transglycosylation activity [99]. These residues could be replaced or repositioned in a manner where hydrolysis can be suppressed. Hansson and Adlercreutz [83] reported that the F426Y mutation of $P$. furiosus $\beta$-glucosidase formed a new hydrogen bond with the substrate. The hydrogen bond was speculated to trap water molecules from reaching the catalytic glutamate and this inhibited hydrolysis activity. Consequently, oligosaccharide yield was improved by $13 \%$ relative to the wild-type. Besides that, the significant increase in the transglycosylation to

(b)

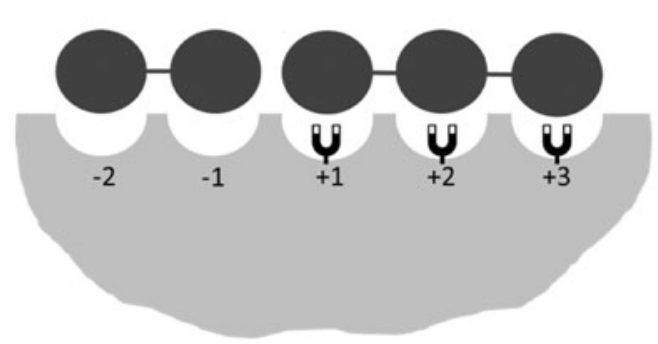

Larger acceptor site allows accommodation of longer sugar acceptor molecule

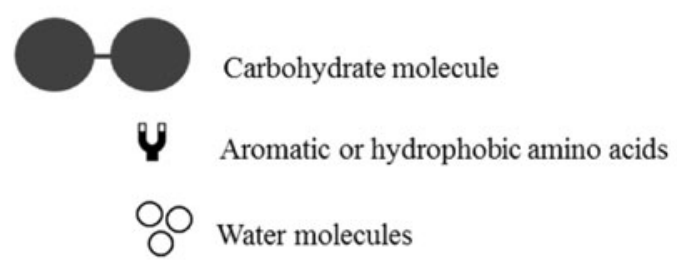

Figure 4. Strategies to modulate active site structure for the increased transglycosylation activity of GHs. (a) Introducing aromatic amino acids or hydrophobic amino acids at the acceptor site. (b) Reducing steric interference to enlarge acceptor site. 
hydrolysis increased the yield of hexyl- $\beta$-glucoside. The mutant also exhibited higher transglycosylation activity at lower water activity than the wild-type enzyme. It was further found that the mutation favored the carbohydrate acceptors to water to react with the glycosylenzyme. Therefore, the increase in oligosaccharide yield displayed by the mutant was due to the increase in the ratio of transglycosylation-to-hydrolysis and a lower rate of the oligosaccharide products hydrolysis [15].

In a separate study, the transglycosylation activity of $\alpha$-galactosidase from Bifidobacterium adolescentis DSM 20083 was improved by $16 \%$ as a result of the H497M mutation. The His497 residue, which was located next to the catalytic Asp496, played the main role in positioning the water molecule for hydrolysis and stabilizing the transition state. Met residue apparently cannot form a hydrogen bond with the water molecule; therefore allowing the carbohydrate molecules to act as acceptors [19]. Water molecules could also be prevented from entering the active site by increasing the hydrophobicity of the active site entrance. This has been successfully demonstrated by the mutation with neopullulanase from B. stearothermophilus TRS40. Mutants with increased hydrophobicity displayed higher transglycosylation activity than the wild-type [17]. Mutation of Trp359 and Tyr377 in B. lehensis G1 maltogenic amylase to a more hydrophobic residue of Phe also improved the synthesis of longer malto-oligosaccharides [100].

Hydrophobicity of the active site was critical for the transglycosylation activity of GHs enzymes. Several studies have reported that when the hydrophobicity surrounding the active site was increased, hydrolysis activity was retarded and transglycosylation activity was enhanced. It was reported that the water molecule could be excluded from entering the active site by increasing the hydrophobicity of the water path entrance. When residues on the entrance path were replaced with more hydrophobic residues, transglycosylation activity was enhanced. In B. stearothermophilus neopullulanase, Y377F, M375L, and S422V mutants produced higher transglycosylation products compared to the wild-type. Hydrolysis activities of all the mutants were also decreased compared to the wild-type. These amino acids were located at the water path entrance near the positive subsite. Therefore, replacing the residues with hydrophobic residues greatly reduced the hydrolysis activity of the enzyme [17]. It has been further demonstrated that the mutation of the region between the third and the fourth conserved region of B. stearothermophilus ET1 maltogenic amylase to a more hydrophobic amino acid displayed 2- to 6-fold higher transglycosylation activity than the wild-type [101].
In the catalytic triad of a chitinase from Serratia marcescens, one of the Asp residues plays a role in positioning and activating the water molecule during hydrolysis [102]. Mutation of this residue caused the active site to disfavor correct positioning of the hydrolytic water molecule during the attack of oxazolinium ion intermediate. The mutation decreased the $K_{m}$ values and caused a subsequent increase in transglycosylation activity. The mutation has been said to affect the catalytic water that lead to lower hydrolysis or increase the probability of nucleophilic attack by a sugar on the oxazolinium ion intermediate [42].

\section{Reducing steric interference}

The presence of bulky amino acid residues in the active site creates steric interference to the bound substrate molecule. One of the promising strategies to improve the production of a longer chain of transglycosylation product is by reducing the steric interference. As illustrated in Figure 4, reduction of steric interference could improve the binding of acceptor molecules for transglycosylation. The transglycosylation activity of $\alpha$-galactosidase from Thermotoga maritima was improved due to the enlargement of the active site entrance introduced by mutation of F328A. As shown in the docking structure model (Figure 5), the replacement of Phe328 with smaller residue caused the acceptor (pNPGal) to have closer contact with the anomeric carbon atom $\mathrm{C} 1$ of the donor galactosyl; therefore, increasing the transglycosylation activity by 16 -fold [103]. In another study, deletion of 580 amino acid residues at the C-terminal of a $\beta$-galactosidase gene from Bifidobacterium bifidum resulted an enzyme with increased transglycosylation and little or no hydrolysis activity. The removal of this segment allowed greater steric access to the active site, thus favoring saccharide acceptors [104].

The volume of the side chain at the subsite +1 is reported to influence hydrolysis and transglycosylation activity. Leemhuis et al. [105] reported that cyclodextrin glucanotransferase was converted to a hydrolase on replacement of Ala located at subsite +1 with Val. The larger side chain of Val introduced steric hindrance for the binding of acceptor at subsite +1 , thus reducing transglycosylation activity dramatically. This is because the sugar acceptor binding at subsite +1 is important to activate the enzyme transglycosylation activity [106]. The size of the amino acid side chain at subsite +1 also determines the type of linkages that could be hydrolyzed or synthesized by the enzyme. It has been shown that enzymes, which hydrolyze only an $\alpha-(1,4)$-glycosidic linkage, have a small amino acid residue at subsite +1 , such as Ala in $\alpha$-amylase. In contrast, enzymes that 

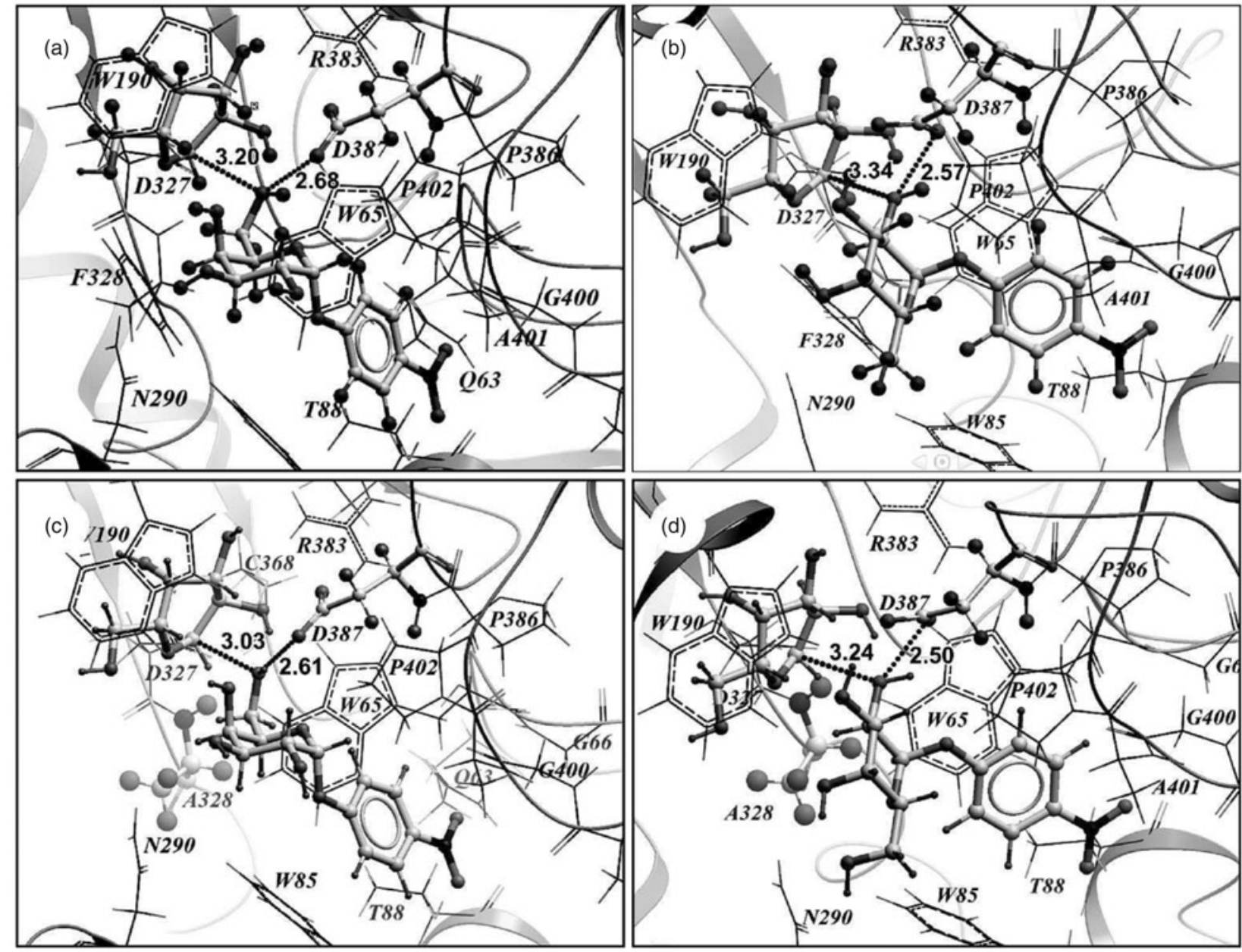

Figure 5. Compared to the wild-type $(a, b)$, mutation of F328A $(c, d)$ of Thermotoga maritime $\alpha$-galactosidase reduced steric interference and caused acceptor molecule (pNPGal) to have closer contact with anomeric carbon atom of the donor galactosyl compared to the wild-type. Catalytic residues Asp327 and Asp387 and mutant residue Ala328 are presented as backbone models. Dotted lines show distances from the atom C1 of the galactosyl anomeric center and from the oxygen atom of the D387 side chain to the oxygen atom of the attacking hydroxyl of pNPGal. Reprinted from Biochemistry (Moscow), Vol. 78, Bobrov et al., Improvement of the efficiency of transglycosylation catalyzed by $\alpha$-galactosidase from Thermotoga maritima by protein engineering, pages 1112-1123, Copyright (2013), with permission from Springer.

hydrolyze the $\alpha-(1,6)$-glycosidic linkage, such as isoamylase and pullulanase, contain a larger residue, such as Leu at this position [107]. It has been suggested that smaller side chain of subsite +1 residue increases the space volume of the active site pocket and reduces van der Waals contact. As a result, hydrogen bond interaction increases, and thus leads to the enhancement of $\alpha$-(1,4)-glycosidic linkage hydrolysis and formation. On the other hand, larger side chain increases van der Waals contact and results in increased $\alpha$ - $(1,6)$-glycosidic linkage hydrolysis and formation [108]. An X-ray crystallographic study of A230V CGTase mutant demonstrated that the mutation to a larger Val residue increased the distance between the side chain with $\mathrm{O}_{3}$ atom of glucose in subsite +1 in a way that causes the sugar to have an improper orientation for hydrolysis or synthesis of the $\alpha$-(1,4)-glycosidic linkage [105]. In another study, the mutation of Trp359 to Phe (Figure 6(a)) reduced the steric interference at subsite +1 of a maltogenic amylase from $B$. lehensis $\mathrm{G} 1$ and caused the modulation of subsite occupation to accommodate a longer acceptor molecule for transglycosylation [100]. Therefore, the steric interference effect at subsite +1 imposes various modulations toward enzyme hydrolysis and transglycosylation.

Mutation of an amino acid at the dimer interface in Thermus sp. maltogenic amylase (ThMA) greatly altered the binding of a substrate and, consequently changed the product specificity of the enzyme. Ala290 is located at the dimer interface and near to the substrate-binding site. From the maltose-ThMA model, Phe289, Val329 of chain A, and Tyr45 of chain B form hydrophobic 
(a)

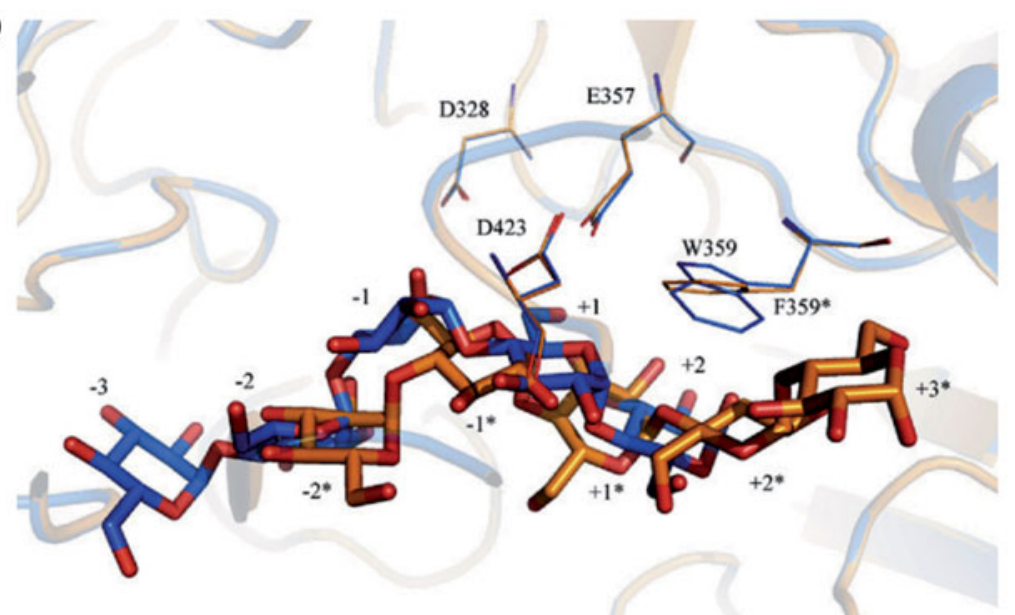

(b)

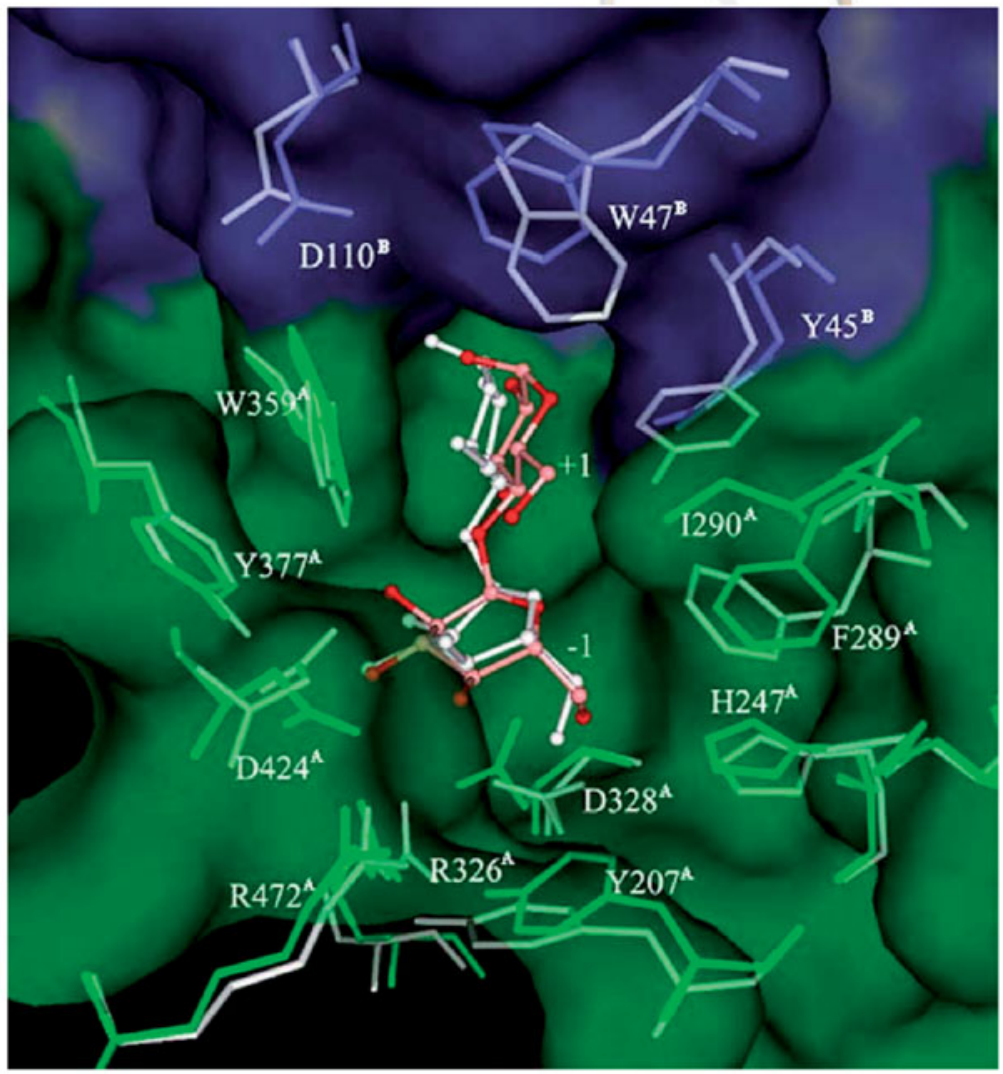

Figure 6. Effects of steric interference to transglycosylation activity. (a) The superimposed wild-type Bacillus lehensis G1 maltogenic amylase and W359F mutant structures are shown in blue and orange, respectively. Reprinted from Process Biochemistry, Vol. 50, Abdul Manas et al., Modulation of transglycosylation and improved malto-oligosaccharide synthesis by protein engineering of maltogenic amylase from Bacillus lehensis G1, pages 1572-1580, Copyright (2015), with permission from Elsevier. (b) Superimposed structure of Thermus sp. maltogenic amylase and A290I mutants. Maltoses in wild-type and A290I mutants are represented in white and red, respectively. Reprinted from Biochimica et Biophysica Acta (BBA) - Proteins and Proteomics, Vol. 1751, Park et al., Mutagenesis of Ala290, which modulates substrate subsite affinity at the catalytic interface of dimeric ThMA, pages 170-177, Copyright (2005), with permission from Elsevier.

interactions with reducing glucose unit of maltose. When Ala290 was substituted with lle, the bulkier side chain of lle protrudes and forces out the side chain of Tyr45 and Phe289; therefore loosening the support for the reducing glucose unit (Figure 6(b)). These conformational changes also resulted in the widening of the catalytic interface, and thus reduced the substrate-binding affinity to maltose. As a consequence, the A290I mutant produced 3.0-10.0 times less glucose from malto-oligosaccharides hydrolysis compared to the wild-type and only $1.0 \%$ glucose was produced from maltose for A290I compared to $11.2 \%$ for the wild-type. 
Moreover, the catalytic efficiency, $\mathrm{k}_{\text {cat }} / \mathrm{K}_{\mathrm{m}}$ of wild-type for maltose was 48 times higher than $A 290 \mathrm{l}$ and the $\mathrm{K}_{\mathrm{m}}$ value toward maltose increased dramatically, which indicated a reduced affinity [109].

\section{Improving the binding of acceptor molecule}

Another protein engineering strategy is to manipulate the structure or properties of the amino acids surrounding the active site in a manner that hydrolysis will be suppressed and transglycosylation will be improved. The modulation of the active site structure by protein engineering has successfully produced enzyme variants with improved transglycosylation activity. This approach requires a deep understanding regarding enzyme structure-function relationship. The influence of the active site structure to the enzyme catalytic properties can be studied by using rational design combined with sitedirected mutagenesis. These methods have become powerful tools to produce GHs variants with high transglycosylation activity. The functional role of specific amino acids at the catalytic region, which are involved in transglycosylation activity, have been elucidated using site-directed mutagenesis [110] and changing of even single amino acids at this region could greatly alter the activity of GHs.

As depicted in Figure 4, one of the key factors to improve acceptor binding is by introducing amino acids that strongly bind sugar molecules at the positive subsite. Several studies have reported the importance of aromatic amino acids in the active site for substrate binding. They form non-polar stacking interactions with the substrate to hold it in a suitable manner for catalysis [92]. Therefore, it is possible to increase transglycosylation activity of GHs by introducing these residues in the positive subsite. A study reported that a group of aromatic residues (Tyr195, Phe183, Phe259, and Phe283) in the active site centers of a natural transferase and Bacillus sp. 1011 cyclodextrin-glycosyltransferase cooperatively play an important role in substrate binding, acceptor binding, and stabilizing the transition-state [111]. Compared to a natural hydrolase, $B$. stearothermophilus $\alpha$-amylase contained small amino acids, such as Ala, Val, and Ser at the homologous position. Transglycosylation activity was introduced into the enzyme by replacing the small residues with aromatic residues. The mutants $\mathrm{A} 289 \mathrm{~F}$ and A289Y produced methyl-maltosides during alcoholysis with methanol from starch, a function which was not exhibited by the wild-type. The mutants also produced longer oligosaccharides than the wild-type enzyme [94]. Besides, transglycosylation can be improved by introducing a new hydrogen bond between the mutated residue and acceptor molecule at the positive subsite. In one study, mutation of F441Y and F359Q in Sulfolobus solfataricus $\beta$-galactosidase also improved the yield of galacto-oligosaccharides produced from lactose. The mutations have introduced a new potential hydrogen bond between the mutated residue and the sugar molecule in the $(+2)$ subsite (Figure 7). The addition of a new hydrogen bond caused the change in the enthalpy and thus led to a decrease in the activation energy as well as stabilizing the catalytic process [21].

The subsite +1 structure of the $\alpha$-amylase family, enzymes play important roles in substrate specificity and transglycosylation activity $[17,92,108,112-117]$.
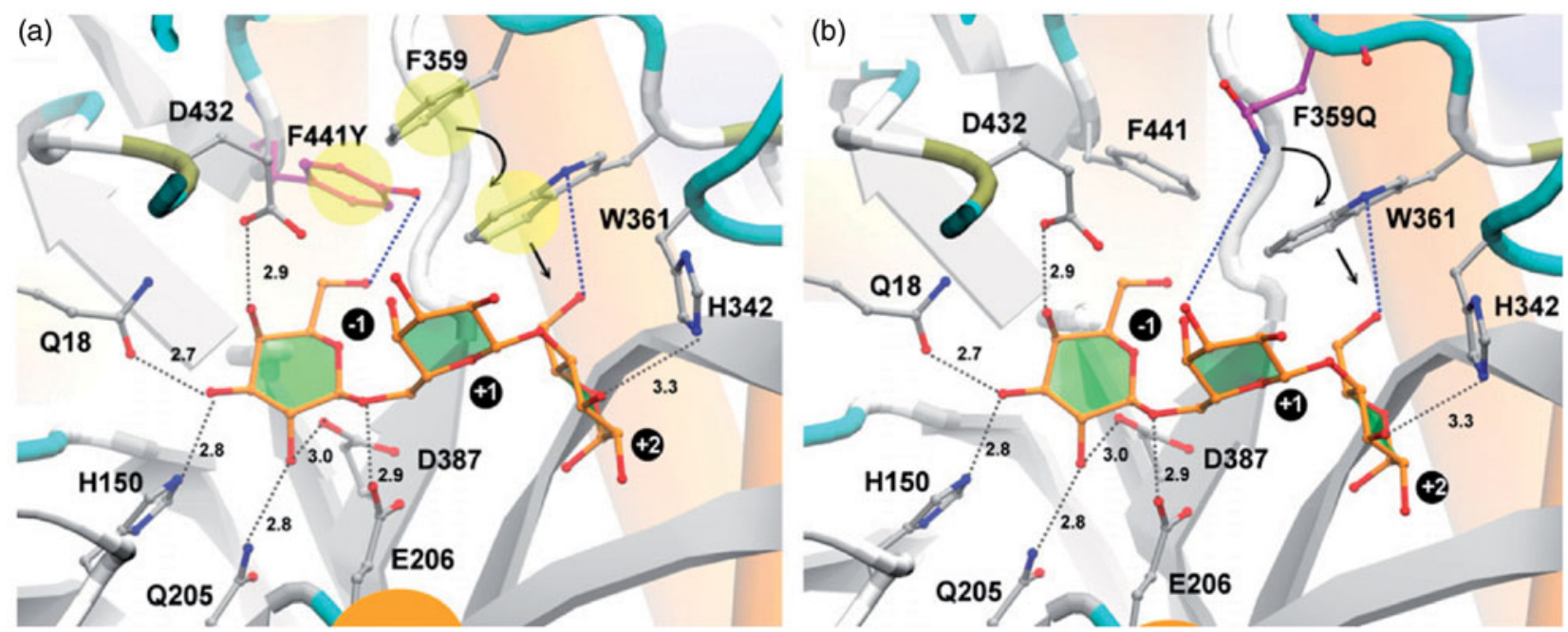

Figure 7. Mutation of F441Y (a) and F359Q (b) in Sulfolobus solfataricus $\beta$-galactosidase introduced new hydrogen bonds between the residues and acceptor molecule at positive subsite. Reprinted from Food Chemistry, Vol. 138, Wu et al., Enhancing the production of galacto-oligosaccharides by mutagenesis of Sulfolobus solfataricus $\beta$-galactosidase, pages 1588-1595, Copyright (2013), with permission from Elsevier. 


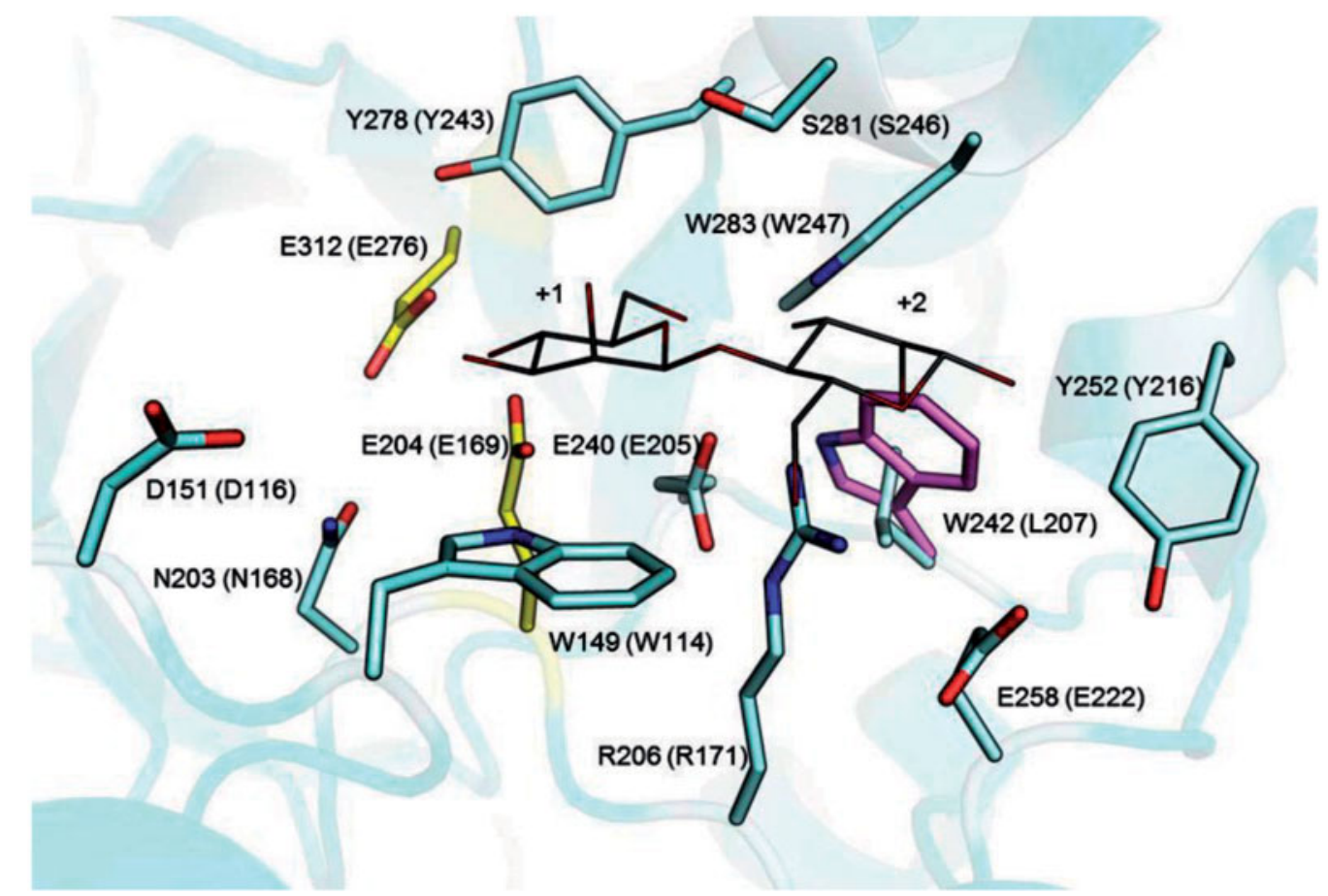

Figure 8. The presence of Trp242 residue (magenta) at a non-conserved position on the positive subsite of $\beta$-mannanases from Aspergillus nidulans is responsible for its high transglycosylation activity compared to homologous enzymes that have Leu (cyan) at the respective position. Mannobiose is shown in gray. Reprinted from Applied Microbiology and Biotechnology, Vol. 98, Rosengren et al., An Aspergillus nidulans $\beta$-mannanase with high transglycosylation capacity revealed through comparative studies within glycosidase family 5, pages 10091-10104, Copyright (2014).

Improving acceptor binding at this subsite has been shown to enhance transglycosylation activity [97]. The affinity of the acceptor molecule in subsite +1 of a chitinase from Arabidopsis thaliana was improved by the introduction of a tryptophan residue at the subsite +1 ; thus, resulted in enhanced transglycosylation activity [118]. A similar finding was demonstrated by G77W mutation at subsite +1 of a chitinase from the Cycas revoluta. The aromatic side chain of tryptophan formed a stacking interaction with the acceptor to enhance its binding affinity for catalyzing an efficient transglycosylation activity. Furthermore, the hydrophobic side chain of tryptophan may repel water molecules, preventing the nucleophilic attack of a water molecule to the carbohydrate intermediate [119]. Similar observation was obtained from the W243F mutation of a $\beta$-glucosidase that moved the interaction from the -1 to the +1 subsite because the new aromatic residue changed to a more favorable position, which resulted in a significant increase of glycosynthase activity [120].

The improvement in the transglycosylation of $\mathrm{GHs}$ has also been demonstrated when the affinity of a positive subsite other than subsite +1 was enhanced. The presence of a non-conserved Trp residue in subsite +2 of a $\beta$-mannanases from Aspergillus nidulans caused the enzyme to exhibit higher transglycosylation activity than other studied enzymes that have Leu at the homologous position. Trp residue contributes to stronger binding of the sugar acceptor at the positive subsite (Figure 8), and thus the enzyme prefers to use saccharides as an acceptor instead of water [28]. Tryptophan is known to be involved in stacking interactions with sugar in the active site of carbohydrate active enzymes $[39,43]$. It was reported that a non-conserved tryptophan located in subsite +1 of a mannanase from Aspergillus nidulans FGSC A4 was responsible for the higher yield of transglycosylation products compared to other studied enzymes which do not have the residue [41]. The favorable acceptor binding contributed by the Trp residues was proved by the lower $\mathrm{K}_{\mathrm{m}}$ value toward mannopentaose and mannohexaose. Arg residue provides mannosyl affinity in subsite +2 of $\beta$-mannanase from Trichoderma reesei. Mutation of this residue to Lys significantly reduced transglycosylation activity [40]. The role of aromatic residues (e.g. Phe and Trp) in providing a strong acceptor binding was similarly demonstrated by chitinases, whereby the substitution of these residues with Ala greatly reduced the amount of transglycosylation products $[44,121]$. The importance of positive subsites for efficient transglycolsylation has also been shown for xylanase [38].

On the other hand, acceptor binding can be enhanced by reducing hydrolysis from mutation of a particular residue. For example, transglycosylation 
performance of $\beta$-galactosidase from Geobacillus stearothermophilus KVE39 has been improved by the mutation of Arg109 residue with Lys, Val, or Trp. The production of a trisaccharide from lactose increased $11.5 \%$ by R109K mutant, $21 \%$ by R109V mutant, and $23 \%$ by $\mathrm{R} 109 \mathrm{~W}$ mutant compared to only $2 \%$ by the wild-type enzyme. It was also demonstrated in Thermus thermophilus $\beta$-galactosidase that the conserved Arg involved in the binding of the galactose molecule by hydrogen bond interaction; therefore, is important for its hydrolytic activity. Replacing this residue caused a decrease in hydrolysis activity, and thus improved the capability of transferring galactose to donors, such as lactose to yield galacto-oligosaccharides [122]. Reducing the negative subsite binding affinity is another strategy that could be used to reduce the hydrolysis activity. Substitution of amino acids of an important subsite will weaken the binding of substrates, thus reducing the hydrolysis. This is generally applicable to the $-\mathrm{n}$ subsites, where binding of donor takes place [123]. Taira et al. [44] has suggested that transglycosylation activity of the family of GH-18 chitinases would be enhanced by mutation of amino acids at $-\mathrm{n}$ subsites, while suppression would result from mutation of amino acids at $+\mathrm{n}$ subsites. Aronson et al. [124] reported that the mutation of Trp167 at the -3 subsite to alanine in Serratia marcescens chitinase significantly enhanced the transglycosylation activity. It was proposed that the decreased binding affinity at subsite -3 due to the mutation increases the frequency of acceptor binding at the positive subsite. A similar finding was reported by Mótyán et al. [125], where the substitution of valine to phenylalanine in barley $\alpha$-amylase caused reduction in binding affinity of subsite -6 ; therefore, increasing its transglycosylation activity. Subsite -6 has a large favorable energy in the wild-type enzyme. Therefore, the mutation affects the hydrolysis of longer substrates. Similar enhancement of transglycosylation was also observed in chemical modifications of residues at $-\mathrm{n}$ subsites of hen egg white lysozyme [126].

\section{Modulating the $p K_{a}$ of catalytic nucleophile}

As depicted in Figure 2, a pair of carboxylic acids is involved in the catalysis in GHs. The catalysis in $\mathrm{GH}$ is $\mathrm{pH}$-dependent which is set by the $\mathrm{p} K_{a}$ values of its catalytic residues. While one of these residues serves as a nucleophile, the other residue plays a dual role as a general acid and general base during glycosylation and deglycosylation, respectively. Such a dual role requires the enzyme to control the ionization state of the general acid/base residue at each step in catalysis. This common occurrence known as " $\mathrm{p} K_{a}$ cycling" has been extensively studied $[127,128]$. Studies have addressed the important of residues surrounding the catalytic amino acids in regulating the process and how the change of these residues influences the optimum $\mathrm{pH}$ of the reaction $[129,130]$. Modulating the $\mathrm{p} K_{a}$ of this catalytic residue was found to be an effective way to improve the transglycosylation to hydrolysis ratio.

Modulation of the $\mathrm{p} K_{\mathrm{a}}$ of an $\alpha$-L-arabinofuranosidase catalytic nucleophile has been shown to improve the

Table 3. Summary of mutations that enhance the transglycosylation activity of various glycosyl hydrolases.

\begin{tabular}{|c|c|c|c|c|}
\hline Strategy & Enzyme & Source & Mutation & $\overline{\text { Reference }}$ \\
\hline \multirow{5}{*}{$\begin{array}{l}\text { Mutation to repel water from enter- } \\
\text { ing active site for enhanced trans- } \\
\text { glycosylation (increased } \\
\text { hydrophobicity) }\end{array}$} & $\beta$-glucosidase & Pyrococcus furiosus & F426Y & [62] \\
\hline & $\alpha$-galactosidase & Bacillus adolescentis DSM 20083 & H497M & [33] \\
\hline & Neopullulanase & Bacillus stearothermophilus TRS40 & Y377F, M375L, S422V & [77] \\
\hline & Maltogenic amylase & Bacillus lehensis G1 & W359F, Y377F & [86] \\
\hline & Maltogenic amylase & Bacillus stearothermophilus ET1 & T383V, G382A/T383V, G382M/T383L & [87] \\
\hline Mutation of Asp in catalytic triad & Chitinases & Serratia marcescens & $\begin{array}{l}\text { D313N (ChiA) } \\
\text { D142N (ChiB) }\end{array}$ & [26] \\
\hline \multirow{6}{*}{$\begin{array}{l}\text { Mutation at positive }(+n) \text { subsite to } \\
\text { enhance acceptor binding }\end{array}$} & Endo- $\beta$-1,4-mannanases & Aspergillus nidulans FGSC A4 & S289W & [25] \\
\hline & Chitinase & Cycas revoluta & G77W & [106] \\
\hline & Chitinase & Arabidopsis thaliana & G75W & [105] \\
\hline & Chitinase & Serratia marcescens & F396W & [26] \\
\hline & $\alpha$-amylase & Bacillus stearothermophilus & A289F, A289Y & [80] \\
\hline & $\beta$-galactosidase & Sulfolobus solfataricus & F441Y, F359Q & [98] \\
\hline \multirow{3}{*}{$\begin{array}{l}\text { Mutation at negative }(-n) \text { subsite to } \\
\text { decrease binding affinity for } \\
\text { enhanced acceptor binding }\end{array}$} & Chitinase & Serratia marcescens & W167A & [112] \\
\hline & $\beta$-galactosidase & Geobacillus stearothermophilus KVE39 & R109K, R109V, R109W & [110] \\
\hline & $\alpha$-amylase & Barley & V47F & [113] \\
\hline $\begin{array}{l}\text { Chemical modification of residue at } \\
\text { negative }(-n) \text { subsite to weaken } \\
\text { substrate binding }\end{array}$ & Lysozyme & Hen egg white & $\begin{array}{l}\text { Chemical modification of D101 and } \\
\text { W62 with D-glucosamine and 2- } \\
\text { nitrophenyl-sulfenyl chloride, } \\
\text { respectively }\end{array}$ & [114] \\
\hline \multirow{3}{*}{$\begin{array}{l}\text { Mutation at positive }(+n) \text { subsite to } \\
\text { reduce steric interference for bind- } \\
\text { ing of longer acceptor molecule }\end{array}$} & Maltogenic amylase & Bacillus lehensis G1 & W359F & [86] \\
\hline & $\alpha$-galactosidase & Thermotoga maritime & $\mathrm{F} 328 \mathrm{~A}$ & [89] \\
\hline & $\beta$-galactosidase & Bifidobacterium bifidum & Deletion of C-terminal & [90] \\
\hline \multirow[t]{2}{*}{$\begin{array}{l}\text { Mutation that changes } \mathrm{p} K_{\mathrm{a}} \text { of cata- } \\
\text { lytic nucleophile }\end{array}$} & $\alpha$-L-arabinofuranosidase & $\begin{array}{r}\text { Thermobacillus } \\
\text { xylanilyticus }\end{array}$ & N344P and N344Y & [119] \\
\hline & $\beta$-glucosidase & Thermotoga neapolitana & $\mathrm{N} 220 \mathrm{Y}$ & [70] \\
\hline
\end{tabular}


transglycosylation reaction. Mutations of N344P and $\mathrm{N} 344 \mathrm{Y}$ which were in close proximity to catalytic nucleophile, caused modulation in the $\mathrm{p} K_{\mathrm{a}}$ of the catalytic residue, hence impacting the optimum $\mathrm{pH}$. The altered optimum $\mathrm{pH}$ affected the ionization state of the catalytic residue to favor interaction with the sugar acceptor, and resulted in an improved ratio of transglycosylation [131]. In another study, mutations of N220Y, $\mathrm{N} 220 \mathrm{~F}$, and N220R in $\beta$-glucosidase from Thermotoga neapolitana, which were located in the second layer of subsite +1 , exhibited a strong $\mathrm{pH}$-dependent hydrolytic reaction but unaffected transglycosylation activity. N220Y mutation altered the $p K_{a}$ values of nucleophile and acid/base residues. While, deprotonation of the catalytic acid at high $\mathrm{pH}$ caused the hydrolytic activity of all three mutants diminished [57].

The strategies discussed above are potentially exploited in synthetic application for the production of oligosaccharides. These mutations and chemical modifications are summarized in Table 3 . Modulation of the active site structure resulted in a higher transglycosylation reaction rate, reduced donor/acceptor concentration, and produced longer oligosaccharides, which suit the industrial demand impeccably. Furthermore, the clear insight of subsite structure and the role of each amino acid in the active site. This provided a platform for the production of an enzyme with tailored function.

\section{Recent advances, future direction an conclusion}

Directed evolution has become a powerful tool to produce enzyme variants with improved desired properties. Directed evolution involves repetitive rounds of gene mutation, recombination, and screening and has been shown to effectively produce enzyme variants that catalyze desired glycoside synthesis [132]. T. thermophilus $\beta$-glycosidase variants with reduced hydrolytic activity and improved transglycosylation activity were successfully produced using directed-evolution strategies. The mutations, which were located just in front of the subsite -1 , improved the affinity of the acceptor by the reposition of the donor molecule in the +1 subsite together with a better fit of the acceptor in the -1 subsite [133]. In another study, the random mutagenesis approach yielded mutants of the arabinofuranosyl hydrolase that could catalyze the transfer of an arabinofuranosyl moiety to various aliphatic alcohol acceptors. The mutants exhibited improved transglycosylation activity up to $96 \%$ compared to the wild-type. However, structural analysis showed that the mutations were not located within or close to the active site [134]. This raises a probability that other parts of the enzyme than the active site might also play a role in the enzyme activity. Site saturation mutagenesis has further shown to be effective in introducing mutation that eliminated hydrolysis activity of $\mathrm{GH}$ without affecting its transglycosylation activity [57]. These studies showed that directed-evolution is a great tool to identify any undetermined amino acids and other parts of the enzyme that might be involved in modulating transglycosylation activity.

This review has highlighted important research that provides a greater understanding of $\mathrm{GH}$ s structure-function and strategies to enhance the transglycosylation activity of the enzymes for oligosaccharide production. This may provide a wider platform for future improvement using GHs as a biocatalyst for oligosaccharide synthesis at a commercial scale. Enhanced transglycosylation activity of $\mathrm{GHs}$ through advances in reaction equilibrium control and modification of active sites resulted in higher oligosaccharides production, which has a great impact on the economics as well as the application of oligosaccharides. The engineered enzyme with tailored function and substrate specificity is valuable to suit the industrial conditions as well as in developing novel oligosaccharides for various applications.

\section{Acknowledgements}

The authors thanked Ahmad Safwan Ideris for proofreading the manuscript.

\section{Disclosure statement}

The authors report no declarations of interest.

\section{Funding}

This work was supported by the Malaysia Genome Institute, Ministry of Science, Technology and Innovation Malaysia under the Project of Structural and Functional Genomics of Glycoside and Peptide Hydrolases from the Extremophiles Glaciozyma antarctica and Bacillus lehensis G1 for the Biobased Economy (No. 02-05-20-SF0007).

\section{References}

[1] Park JH, You JY, Shim OH, et al. Growth effect of branched oligosaccharides on principal intestinal bacteria. Korean J Microbiol Biotechnol. 1992;20: 237-242.

[2] Oku T, Nakamura S. Digestion, absorption, fermentation, and metabolism of functional sugar substitutes and their available energy. Pure Appl Chem. 2002;74: 1253-1261.

[3] Prapulla SG, Subhaprada V, Karanth NG. Microbial production of oligosaccharides: a review. Adv Appl Microbiol. 2000;47:299-343. 
[4] Hancock SM, Vaughan MD, Withers SG. Engineering of glycosidases and glycosyltransferases. Curr Opin Chem Biol. 2006;10:509-519.

[5] Bojarová P, Křen V. Glycosidases: a key to tailored carbohydrates. Trends Biotechnol. 2009;27:199-209.

[6] Section LILMI. Future directions for the global functional foods market. Leatherhead Food Research (Market Intelligence Section); 2011. no. 9781907895227.

[7] Patel S, Goyal A. Functional oligosaccharides: production, properties and applications. World J Microbiol Biotechnol. 2010;27:1119-1128.

[8] Mackenzie LF, Wang Q, Warren RAJ, et al. Glycosynthases: mutant glycosidases for oligosaccharide synthesis. J Am Chem Soc. 1998;120:5583-5584.

[9] Wang LX, Huang W. Enzymatic transglycosylation for glycoconjugate synthesis. Curr Opin Chem Biol. 2009;13:592-600.

[10] Scigelova M, Singh S, Crout DHG. Glycosidases: a great synthetic tool. J Mol Catal B Enzym. 1999;6: 483-494.

[11] Crout DHG, Vic G. Glycosidases and glycosyl transferases in glycoside and oligosaccharide synthesis. Curr Opin Chem Biol. 1998;2:98-111.

[12] Palcic MM. Biocatalytic synthesis of oligosaccharides. Curr Opin Biotechnol. 1999;10:616-624.

[13] Bucke C. Oligosaccharide synthesis using glycosidases*. J Chem Technol Biotechnol. 1996;67: 217-220.

[14] Weijers CAGM, Franssen MCR, Visser GM. Glycosyltransferase-catalyzed synthesis of bioactive oligosaccharides. Biotechnol Adv. 2008;26:436-456.

[15] Hansson T, Kaper T, van der Oost J, et al. Improved oligosaccharide synthesis by protein engineering of beta-glucosidase CelB from hyperthermophilic Pyrococcus furiosus. Biotechnol Bioeng. 2001;73: 203-210.

[16] Abdul Manas NH, Pachelles S, Mahadi NM, et al. The characterisation of an alkali-stable maltogenic amylase from Bacillus lehensis $\mathrm{G} 1$ and improved malto-oligosaccharide production by hydrolysis suppression. PLoS One. 2014;9:e106481.

[17] Kuriki T, Kaneko $H$, Yanase $M$, et al. Controlling substrate preference and transglycosylation activity of neopullulanase by manipulating steric constraint and hydrophobicity in active center. J Biol Chem. 1996;271:17321-17329.

[18] Fernández-Arrojo L, Marín D, Gómez De Segura A, et al. Transformation of maltose into prebiotic isomaltooligosaccharides by a novel $\alpha$-glucosidase from Xantophyllomyces dendrorhous. Process Biochem. 2007;42:1530-1536.

[19] Hinz SWA, Doeswijk-Voragen CHL, Schipperus R, et al. Increasing the transglycosylation activity of $\alpha$-galactosidase from Bifidobacterium adolescentis DSM 20083 by site-directed mutagenesis. Biotechnol Bioeng. 2006;93:122-131.

[20] Park HY, Kim HJ, Lee JK, et al. Galactooligosaccharide production by a thermostable $\beta$-galactosidase from Sulfolobus solfataricus. World J Microbiol Biotechnol. 2008;24:1553-1558.
[21] Wu Y, Yuan S, Chen S, et al. Enhancing the production of galacto-oligosaccharides by mutagenesis of Sulfolobus solfataricus $\beta$-galactosidase. Food Chem. 2013;138:1588-1595.

[22] Lorenzoni ASG, Aydos LF, Klein MP, et al. Fructooligosaccharides synthesis by highly stable immobilized $\beta$-fructofuranosidase from Aspergillus aculeatus. Carbohydr Polym. 2014;103:193-197.

[23] Li M, Seo S, Karboune S. Bacillus amyloliquefaciens levansucrase-catalyzed the synthesis of fructooligosaccharides, oligolevan and levan in maple syrupbased reaction systems. Carbohydr Polym. 2015;133: 203-212.

[24] Aragon CC, Mateo C, Ruiz-Matute $\mathrm{Al}$, et al. Production of xylo-oligosaccharides by immobilizedstabilized derivatives of endo-xylanase from Streptomyces halstedii. Process Biochem. 2013;48: 478-483.

[25] Wan Azelee NI, Jahim JM, Ismail AF, et al. High xylooligosaccharides (XOS) production from pretreated kenaf stem by enzyme mixture hydrolysis. Ind Crop Prod. 2016;81:11-19.

[26] Zang $\mathrm{H}$, Xie $\mathrm{S}, \mathrm{Wu} \mathrm{H}$, et al. A novel thermostable GH5_7 $\beta$-mannanase from Bacillus pumilus GBSW19 and its application in manno-oligosaccharides (MOS) production. Enzyme Microb Technol. 2015;78:1-9.

[27] Jian HL, Zhu LW, Zhang WM, et al. Enzymatic production and characterization of manno-oligosaccharides from Gleditsia sinensis galactomannan gum. Int J Biol Macromol. 2013;55:282-288.

[28] Rosengren A, Reddy SK, Sjöberg JS, et al. An Aspergillus nidulans $\beta$-mannanase with high transglycosylation capacity revealed through comparative studies within glycosidase family 5 . Appl Microbiol Biotechnol. 2014;98:10091-10104.

[29] Song JY, Alnaeeli M, Park JK. Efficient digestion of chitosan using chitosanase immobilized on silica-gel for the production of multisize chitooligosaccharides. Process Biochem. 2014;49:2107-2113.

[30] Sinha S, Dhakate SR, Kumar P, et al. Electrospun polyacrylonitrile nanofibrous membranes for chitosanase immobilization and its application in selective production of chitooligosaccharides. Bioresour Technol. 2012;115:152-157.

[31] Díez-Municio $M$, de las Rivas $B$, Jimeno $M L$, et al. Enzymatic synthesis and characterization of fructooligosaccharides and novel maltosylfructosides by inulosucrase from Lactobacillus gasseri DSM 20604. Appl Environ Microbiol. 2013;79:4129-4140.

[32] Davies G, Henrissat B. Structures and mechanisms of glycosyl hydrolases. Structure. 1995;3:853-859.

[33] Davies GJ, Wilson KS, Henrissat B. Nomenclature for sugar-binding subsites in glycosyl hydrolases. Biochem J. 1997;321:557-559.

[34] Koshland DE. Stereochemistry and the mechanism of enzymatic reactions. Biol Rev. 1953;28:416-436.

[35] Raich L, Borodkin V, Fang W, et al. A trapped covalent intermediate of a glycoside hydrolase on the pathway to transglycosylation. insights from experiments and quantum mechanics/molecular mechanics simulations. J Am Chem Soc. 2016;138:3325-3332. 
[36] van der Maarel MJEC, van der Veen B, Uitdehaag JCM, et al. Properties and applications of starchconverting enzymes of the alpha-amylase family. J Biotechnol. 2002;94:137-155.

[37] Schmidt A, Gübitz GM, Kratky C. Xylan binding subsite mapping in the xylanase from Penicillium simplicissimum using xylooligosaccharides as cryoprotectant. Biochemistry. 1999;38:2403-2412.

[38] Armand S, Andrews SR, Charnock SJ, et al. Influence of the aglycone region of the substrate binding cleft of Pseudomonas xylanase 10A on catalysis. Biochemistry. 2001;40:7404-7409.

[39] Larsson AM, Anderson L, Xu B, et al. Three-dimensional crystal structure and enzymic characterization of beta-mannanase Man5A from blue mussel Mytilus edulis. J Mol Biol. 2006;357:1500-1510.

[40] Rosengren A, Hägglund P, Anderson LS, et al. The role of subsite +2 of the Trichoderma reesei betamannanase TrMan5A in hydrolysis and transglycosylation. Biocatal Biotransform. 2012;30:338-352.

[41] Dilokpimol A, Nakai $\mathrm{H}$, Gotfredsen $\mathrm{CH}$, et al. Recombinant production and characterisation of two related GH5 endo- $\beta$-1,4-mannanases from Aspergillus nidulans FGSC A4 showing distinctly different transglycosylation capacity. Biochim Biophys Acta. 2011;1814:1720-1729.

[42] Zakariassen $H$, Hansen MC, Joøranli $M$, et al. Mutational effects on transglycosylating activity of family 18 chitinases and construction of a hypertransglycosylating mutant. Biochemistry. 2011;50: 5693-5703.

[43] Eide KB, Lindbom AR, Eijsink VGH, et al. Analysis of productive binding modes in the human chitotriosidase. FEBS Lett. 2013:587:3508-3513.

[44] Taira T, Fujiwara $M$, Dennhart $N$, et al. Transglycosylation reaction catalyzed by a class $\mathrm{V}$ chitinase from cycad, Cycas revoluta: a study involving site-directed mutagenesis, HPLC, and real-time ESIMS. Biochim Biophys Acta. 2010;1804:668-675.

[45] Williams SJ, Withers SG. Glycosyl fluorides in enzymatic reactions. Carbohydr Res. 2000;327:27-46.

[46] Lu L, Xiao M, Xu X, et al. A novel beta-galactosidase capable of glycosyl transfer from Enterobacter agglomerans B1. Biochem Biophys Res Commun. 2007;356:78-84.

[47] Torres DPM, Gonçalves MdPF Teixeira JA, et al. Galacto-oligosaccharides: production, properties, applications, and significance as prebiotics. Compr Rev Food Sci Food Saf. 2010;9:438-454.

[48] Seo $\mathrm{DH}$, Jung $\mathrm{JH}, \mathrm{Ha}$ SJ, et al. Molecular cloning of the amylosucrase gene from a moderate thermophilic bacterium Deinococcus geothermalis and analysis of its dual enzyme activity. In: Park $\mathrm{KH}$, editor. Carbohydrate-active enzymes. Cambridge (UK): Woodhead Publishing; 2008. p. 125-140.

[49] Murata $T$, Honda $H$, Hattori $T$, et al. Enzymatic synthesis of poly- $\mathrm{N}$-acetyllactosamines as potential substrates for endo- $\beta$-galactosidase-catalyzed hydrolytic and transglycosylation reactions. Biochim Biophys Acta. 2005;1722:60-68.

[50] Zervosen A, Nieder V, Gutiérrez Gallego R, et al. Synthesis of nucleotide-activated oligosaccharides by beta-galactosidase from Bacillus circulans. Biol Chem. 2001;382:299-311.

[51] Falconer DJ, Mukerjea R, Robyt JF. Biosynthesis of dextrans with different molecular weights by selecting the concentration of Leuconostoc mesenteroides B-512FMC dextransucrase, the sucrose concentration, and the temperature. Carbohydr Res. 2011;346: 280-284.

[52] Tieking M, Ehrmann MA, Vogel RF, et al. Molecular and functional characterization of a levansucrase from the sourdough isolate Lactobacillus sanfranciscensis TMW 1.392. Appl Microbiol Biotechnol. 2005;66:655-663.

[53] Bonnin E, Vigouroux J, Thibault JF. Kinetic parameters of hydrolysis and transglycosylation catalyzed by an exo- $\beta$ - $(1,4)$-galactanase. Enzyme Microb Technol. 1997;20:516-522.

[54] Saitoh H, Takagaki K, Majima M, et al. Enzymic reconstruction of glycosaminoglycan oligosaccharide chains using the transglycosylation reaction of bovine testicular hyaluronidase. J Biol Chem. 1995;270:3741-3747.

[55] Oikawa T, Tsukagawa $Y$, Chino $M$, et al. Increased transglycosylation activity of Rhodotorula glutinis endo-beta-glucanase in media containing organic solvent. Biosci Biotechnol Biochem. 2001;65: 1889-1892.

[56] Seidle HF, Huber RE. Transglucosidic reactions of the Aspergillus niger Family 3 beta-glucosidase: qualitative and quantitative analyses and evidence that the transglucosidic rate is independent of $\mathrm{pH}$. Arch Biochem Biophys. 2005;436:254-264.

[57] Lundemo P, Karlsson EN, Adlercreutz P. Eliminating hydrolytic activity without affecting the transglycosylation of a GH1 $\beta$-glucosidase. Appl Microbiol Biotechnol. 2016;101:1121-1131.

[58] Petzelbauer I, Reiter A, Splechtna B, et al. Transgalactosylation by thermostable beta-glycosidases from Pyrococcus furiosus and Sulfolobus solfataricus. Binding interactions of nucleophiles with the galactosylated enzyme intermediate make major contributions to the formation of new beta-glycosides during lactose conversion. Eur J Biochem. 2000;267: 5055-5066.

[59] Park KH, Kim MJ, Lee HS, et al. Transglycosylation reactions of Bacillus stearothermophilus maltogenic amylase with acarbose and various acceptors. Carbohydr Res. 1998;313:235-246.

[60] Lee HY, Kim MJ, Baek JS, et al. Preparation and characterization of maltosyl-sucrose isomers produced by transglycosylation of maltogenic amylase from Bacillus stearothermophilus. J Mol Catal B Enzym. 2003;26:293-305.

[61] Roh HJ, Kang SC, Lee HS, et al. Transglycosylation of tagatose with maltotriose by Bacillus stearothermophilus maltogenic amylase (BSMA). Tetrahedron Asymmetry. 2005;16:77-82.

[62] Lee SJ, Kim JC, Kim MJ, et al. Transglycosylation of naringin by Bacillus stearothermophilusMaltogenic amylase to give glycosylated naringin. J Agric Food Chem. 1999;47:3669-3674. 
[63] Kim TJ, Kim MJ, Kim BC, et al. Modes of action of acarbose hydrolysis and transglycosylation catalyzed by a thermostable maltogenic amylase, the gene for which was cloned from a Thermus strain. Appl Environ Microbiol. 1999;65:1644-1651.

[64] Yang SJ, Lee HS, Kim JW, et al. Enzymatic preparation of maltohexaose, maltoheptaose, and maltooctaose by the preferential cyclomaltooligosaccharide (cyclodextrin) ring-opening reaction of Pyrococcus furiosus thermostable amylase. Carbohydr Res. 2006;341: 420-424.

[65] Li X, Li D, Yin Y, et al. Characterization of a recombinant amylolytic enzyme of hyperthermophilic archaeon Thermofilum pendens with extremely thermostable maltogenic amylase activity. Appl Microbiol Biotechnol. 2010;85:1821-1830.

[66] Mahoney RR. Galactosyl-oligosaccharide formation during lactose hydrolysis: a review. Food Chem. 1998;63:147-154.

[67] Kang GJ, Kim MJ, Kim JW, et al. Immobilization of thermostable maltogenic amylase from Bacillus stearothermophilus for continuous production of branched oligosaccharides. J Agric Food Chem. 1997;45: 4168-4172.

[68] Tian F, Karboune S. Enzymatic synthesis of fructooligosaccharides by levansucrase from Bacillus amyloliquefaciens: specificity, kinetics, and product characterization. J Mol Catal B Enzym. 2012;82:71-79.

[69] Mangas-Sánchez J, Adlercreutz P. Enzymatic preparation of oligosaccharides by transglycosylation: a comparative study of glucosidases. J Mol Catal B Enzym. 2015;122:51-55.

[70] Martínez-Villaluenga C, Cardelle-Cobas A, Corzo N, et al. Optimization of conditions for galactooligosaccharide synthesis during lactose hydrolysis by $\beta$-galactosidase from Kluyveromyces lactis (Lactozym 3000 L HP G). Food Chem. 2008;107:258-264.

[71] Faijes $M$, Pérez $X$, Pérez $O$, et al. Glycosynthase activity of bacillus licheniformis 1,3-1,4- $\beta$-glucanase mutants: specificity, kinetics, and mechanism. Biochemistry (Mosc). 2003;42:13304-13318.

[72] Kumar S, Khare SK. Purification and characterization of maltooligosaccharide-forming $\alpha$-amylase from moderately halophilic Marinobacter sp. EMB8. Bioresour Technol. 2012;116:247-251.

[73] Fan JQ, Takegawa K, Iwahara S, et al. Enhanced transglycosylation activity of Arthrobacter protophormiae Endo-N-acetylglucosaminidase in media containing organic solvents. J Biol Chem. 1995;270:17723-17729.

[74] Doukyu N, Yamagishi W, Kuwahara H, et al. Purification and characterization of a maltooligosaccharide-forming amylase that improves product selectivity in water-miscible organic solvents, from dimethylsulfoxide-tolerant Brachybacterium sp. strain LB25. Extremophiles. 2007;11:781-788.

[75] Klibanov AM. Why are enzymes less active in organic solvents than in water? Trends Biotechnol. 1997;15: 97-101.

[76] Srisimarat W, Pongsawasdi P. Enhancement of the oligosaccharide synthetic activity of $\beta$-galactosidase in organic solvents by cyclodextrin. Enzyme Microb Technol. 2008;43:436-441.
[77] Ooe Y, Yamamoto S, Kobayashi $M$, et al. Increase of catalytic activity of $\alpha$-chymotrypsin in organic solvent by co-lyophilization with cyclodextrins. Biotechnol Lett. 1999;21:385-389.

[78] Hasegawa $M$, Yamamoto $S$, Kobayashi $M$, et al. Catalysis of protease/cyclodextrin complexes in organic solvents: effects of reaction conditions and cyclodextrin structure on catalytic activity of proteases. Enzyme Microb Technol. 2003;32:356-361.

[79] Griebenow K, Laureano YD, Santos AM, et al. Improved enzyme activity and enantioselectivity in organic solvents by methyl- $\beta$-cyclodextrin. J Am Chem Soc. 1999;121:8157-8163.

[80] Santos AM, Montañez Clemente IM, Barletta G, et al. Activation of serine protease subtilisin Carlsberg in organic solvents: combined effect of methyl- $\beta$-cyclodextrin and water. Biotechnol Lett. 1999;21: 1113-1118.

[81] Usui T, Matsui H, Isobe K. Enzymic synthesis of useful chito-oligosaccharides utilizing transglycosylation by chitinolytic enzymes in a buffer containing ammonium sulfate. Carbohydr Res. 1990;203:65-77.

[82] Cruz-Guerrero AE, Gómez-Ruiz L, Viniegra-González $\mathrm{G}$, et al. Influence of water activity in the synthesis of galactooligosaccharides produced by a hyperthermophilic $\beta$-glycosidase in an organic medium. Biotechnol Bioeng. 2006;93:1123-1129.

[83] Hansson T, Adlercreutz P. Enhanced transglucosylation/hydrolysis ratio of mutants of Pyrococcus furiosus beta-glucosidase: effects of donor concentration, water content, and temperature on activity and selectivity in hexanol. Biotechnol Bioeng. 2001;75: 656-665.

[84] Kim D, Robyt JF, Lee SY, et al. Dextran molecular size and degree of branching as a function of sucrose concentration, $\mathrm{pH}$, and temperature of reaction of Leuconostoc mesenteroides B-512FMCM dextransucrase. Carbohydr Res. 2003;338:1183-1189.

[85] Gosling A, Stevens GW, Barber AR, et al. Recent advances refining galactooligosaccharide production from lactose. Food Chem. 2010;121:307-318.

[86] Gebler JC, Trimbur DE, Warren RAJ, et al. Substrateinduced inactivation of a crippled.beta.-glucosidase mutant: identification of the labeled amino acid and mutagenic analysis of its role. Biochemistry (Mosc). 1995;34:14547-14553.

[87] Malet C, Planas A. From beta-glucanase to beta-glucansynthase: glycosyl transfer to alpha-glycosyl fluorides catalyzed by a mutant endoglucanase lacking its catalytic nucleophile. FEBS Lett. 1998;440:208-212.

[88] Rastall RA, Bucke C. Enzymatic synthesis of oligosaccharides. Biotechnol Genet Eng Rev. 1992;10: 253-282.

[89] Badieyan S, Bevan DR, Zhang C. Probing the active site chemistry of $\beta$-glucosidases along the hydrolysis reaction pathway. Biochemistry (Mosc). 2012;51: 8907-8918.

[90] Bissaro B, Monsan P, Fauré R, et al. Glycosynthesis in a waterworld: new insight into the molecular basis of transglycosylation in retaining glycoside hydrolases. Biochem J. 2015;467:17-35. 
[91] Sun $Y$, Duan X, Wang L, et al. Enhanced maltose production through mutagenesis of acceptor binding subsite +2 in Bacillus stearothermophilus maltogenic amylase. J Biotechnol. 2016;217:53-61.

[92] Matsui I, Yoneda S, Ishikawa K, et al. Roles of the aromatic residues conserved in the active center of Saccharomycopsis a-amylase for transglycosylation and hydrolysis activity. Biochemistry. 1994;33: 451-458.

[93] Strokopytov B, Knegtel RMA, Penninga D, et al. Structure of cyclodextrin glycosyltransferase complexed with a maltononaose inhibitor at $2.6 \AA$ resolution. Implications for product specificity. Biochemistry. 1996;35:4241-4249.

[94] Saab-Rincón G, del-Río G, Santamaría RI, et al. Introducing transglycosylation activity in a liquefying $\alpha$-amylase. FEBS Lett. 1999;453:100-106.

[95] Remenyik J, Ragunath C, Ramasubbu N, et al. Introducing transglycosylation activity into human salivary $\alpha$-amylase (HSA). Org Lett. 2003;5:4895-4898.

[96] Ohtaki A, Kondo S, Shimura Y, et al. Role of Phe286 in the recognition mechanism of cyclomaltooligosaccharides (cyclodextrins) by Thermoactinomyces vulgaris R-47 alpha-amylase 2 (TVAll). X-ray structures of the mutant TVAlls, F286A and F286Y, and kinetic analyses of the Phe286-replaced mutant TVAlls. Carbohydr Res. 2001;334:309-313.

[97] Durand J, Biarnés $X$, Watterlot $L$, et al. A single point mutation alters the transglycosylation/hydrolysis partition, significantly enhancing the synthetic capability of an endo-glycoceramidase. ACS Catal. 2016;6: 8264-8275.

[98] Tang SY, Yang SJ, Cha H, et al. Contribution of W229 to the transglycosylation activity of 4 - $\alpha$-glucanotransferase from Pyrococcus furiosus. Biochim Biophys Acta. 2006;1764:1633-1638.

[99] Brzozowski AM, Davies GJ. Structure of the Aspergillus oryzae alpha-amylase complexed with the inhibitor acarbose at $2.0 \mathrm{~A}$ resolution. Biochemistry. 1997;36:10837-10845.

[100] Abdul Manas NH, Jonet MA, Abdul Murad AM, et al. Modulation of transglycosylation and improved malto-oligosaccharide synthesis by protein engineering of maltogenic amylase from Bacillus lehensis G1. Process Biochem. 2015;50:1572-1580.

[101] Cha HJ, Yoon HG, Kim YW, et al. Molecular and enzymatic characterization of a maltogenic amylase that hydrolyzes and transglycosylates acarbose. Eur J Biochem. 1998;253:251-262.

[102] Jitonnom J, Lee VS, Nimmanpipug P, et al. Quantum mechanics/molecular mechanics modeling of substrate-assisted catalysis in family 18 chitinases: conformational changes and the role of Asp142 in catalysis in ChiB. Biochemistry (Mosc). 2011;50: 4697-4711.

[103] Bobrov KS, Borisova AS, Eneyskaya EV, et al. Improvement of the efficiency of transglycosylation catalyzed by $\alpha$-galactosidase from Thermotoga maritima by protein engineering. Biochemistry Moscow). 2013;78:1112-1123.

[104] Jørgensen F, Hansen O, Stougaard P. High-efficiency synthesis of oligosaccharides with a truncated beta- galactosidase from Bifidobacterium bifidum. Appl Microbiol Biotechnol. 2001;57:647-652.

[105] Leemhuis $H$, Rozeboom $H J$, Wilbrink $M$, et al. Conversion of cyclodextrin glycosyltransferase into a starch hydrolase by directed evolution: the role of alanine 230 in acceptor subsite +1 . Biochemistry. 2003;42:7518-7526.

[106] Uitdehaag JCM, van Alebeek GJWM, van der Veen $B A$, et al. Structures of maltohexaose and maltoheptaose bound at the donor sites of cyclodextrin glycosyltransferase give insight into the mechanisms of transglycosylation activity and cyclodextrin size specificity. Biochemistry. 2000;39:7772-7780.

[107] Katsuya $Y$, Mezaki $Y$, Kubota $M$, et al. Three-dimensional structure of Pseudomonas isoamylase at $2.2 \mathrm{~A}$ resolution. J Mol Biol. 1998;281:885-897.

[108] Ito $\mathrm{K}$, Ito $\mathrm{S}$, Ishino $\mathrm{K}$, et al. Val326 of Thermoactinomyces vulgaris R-47 amylase II modulates the preference for alpha-(1,4)- and alpha-(1,6)glycosidic linkages. Biochim Biophys Acta. 2007; 1774:443-449.

[109] Park SH, Cha H, Kang HK, et al. Mutagenesis of Ala290, which modulates substrate subsite affinity at the catalytic interface of dimeric ThMA. Biochim Biophys Acta. 2005;1751:170-177.

[110] Homann A, Biedendieck R, Götze S, et al. Insights into polymer versus oligosaccharide synthesis: mutagenesis and mechanistic studies of a novel levansucrase from Bacillus megaterium. Biochem J. 2007;407:189-198.

[111] Nakamura A, Haga K, Yamane K. Four aromatic residues in the active center of cyclodextrin glucanotransferase from alkalophilic Bacillus sp. 1011: effects of replacements on substrate binding and cyclization characteristics. Biochemistry. 1994;33: 9929-9936.

[112] Ibuka A, Tonozuka T, Matsuzawa $H$, et al. Conversion of neopullulanase-alpha-amylase from Thermoactinomyces vulgaris R-47 into an amylopullulanse-type enzyme. J Biochem. 1998;123:275-282.

[113] Abe A, Tonozuka T, Sakano Y, et al. Complex structures of Thermoactinomyces vulgaris R-47 alpha-amylase 1 with malto-oligosaccharides demonstrate the role of domain $\mathrm{N}$ acting as a starch-binding domain. J Mol Biol. 2004;335:811-822.

[114] Kim TJ, Park CS, Cho HY, et al. Role of the glutamate 332 residue in the transglycosylation activity of Thermus maltogenic amylase. Biochemistry. 2000;39: 6773-6780.

[115] Shimura Y, Wang Q, Sakano Y. Subsite structure of $\alpha$-amylase II from Thermoactinomyces vulgaris R-47. Biosci Biotechnol Biochem. 1999;63:2199-2201.

[116] MacGregor EA, Janeček Š, Svensson B. Relationship of sequence and structure to specificity in the alphaamylase family of enzymes. Biochim Biophys Acta. 2001;1546:1-20.

[117] Talens-Perales D, Polaina J, Marín-Navarro J. Structural dissection of the active site of thermotoga maritima $\beta$-galactosidase identifies key residues for transglycosylating activity. J Agric Food Chem. 2016;64:2917-2924. 
[118] Umemoto $N$, Ohnuma $T$, Mizuhara $M$, et al. Introduction of a tryptophan side chain into subsite +1 enhances transglycosylation activity of a $\mathrm{GH}-18$ chitinase from Arabidopsis thaliana, AtChiC. Glycobiology. 2013;23:81-90.

[119] Umemoto N, Ohnuma T, Osawa T, et al. Modulation of the transglycosylation activity of plant family GH18 chitinase by removing or introducing a tryptophan side chain. FEBS Lett. 2015;589:2327-2333.

[120] Pozzo T, Romero-García J, Faijes M, et al. Rational design of a thermostable glycoside hydrolase from family 3 introduces $\beta$-glycosynthase activity. Glycobiology. 2016;27:165-175.

[121] Lü Y, Yang $\mathrm{H}, \mathrm{Hu} \mathrm{H}$, et al. Mutation of Trp137 to glutamate completely removes transglycosyl activity associated with the Aspergillus fumigatus AfChiB1. Glycoconj J. 2009;26:525-534.

[122] Placier G, Watzlawick $H$, Rabiller $C$, et al. Evolved bgalactosidases from Geobacillus stearothermophilus with improved transgalactosylation yield for galactooligosaccharide production. Appl Environ Microbiol. 2009;75:6312-6321.

[123] Eide KB, Stockinger LW, Lewin AS, et al. The role of active site aromatic residues in substrate degradation by the human chitotriosidase. Biochimica Et Biophysica Acta (BBA). 2016;1864:242-247.

[124] Aronson JRNN, Halloran BA, Alexeyev MF, et al. Mutation of a conserved tryptophan in the chitinbinding cleft of Serratia marcescens chitinase A enhances transglycosylation. Biosci Biotechnol Biochem. 2006;70:243-251.

[125] Mótyán JA, Fazekas $E$, Mori $H$, et al. Transglycosylation by barley $\alpha$-amylase 1 . J Mol Catal B Enzym. 2011;72:229-237.
[126] Fukamizo T, Goto S, Torikata T, et al. Enhancement of transglycosylation activity of lysozyme by chemical modification. Agric Biol Chem. 1989;53:2641-2651.

[127] Mclntosh LP, Hand G, Johnson PE, et al. The pKa of the general acid/base carboxyl group of a glycosidase cycles during catalysis: a 13C-NMR study of bacillus circulans xylanase. Biochemistry (Mosc). 1996;35:9958-9966.

[128] Vasella A, Davies GJ, Böhm M. Glycosidase mechanisms. Curr Opin Chem Biol. 2002;6:619-629.

[129] Joshi MD, Sidhu G, Pot I, et al. Hydrogen bonding and catalysis: a novel explanation for how a single amino acid substitution can change the ph optimum of a glycosidase1. J Mol Biol. 2000;299:255-279.

[130] Ludwiczek ML, D'Angelo I, Yalloway GN, et al. Strategies for modulating the $\mathrm{pH}$-dependent activity of a family 11 glycoside hydrolase. Biochemistry (Mosc). 2013;52:3138-3156.

[131] Bissaro B, Saurel O, Arab-Jaziri F, et al. Mutation of a $\mathrm{pH}$-modulating residue in a $\mathrm{GH} 51 \alpha$-l-arabinofuranosidase leads to a severe reduction of the secondary hydrolysis of transfuranosylation products. Biochimica Et Biophysica Acta (BBA). 2014;1840:626-636.

[132] Kittl R, Withers SG. New approaches to enzymatic glycoside synthesis through directed evolution. Carbohydr Res. 2010;345:1272-1279.

[133] Feng HY. Converting a \{beta\}-glycosidase into a \{beta\}-transglycosidase by directed evolution. J Biol Chem. 2005;280:37088-37097.

[134] Pennec A, Daniellou R, Loyer P, et al. Araf51 with improved transglycosylation activities: one engineered biocatalyst for one specific acceptor. Carbohydr Res. 2015;402:50-55. 